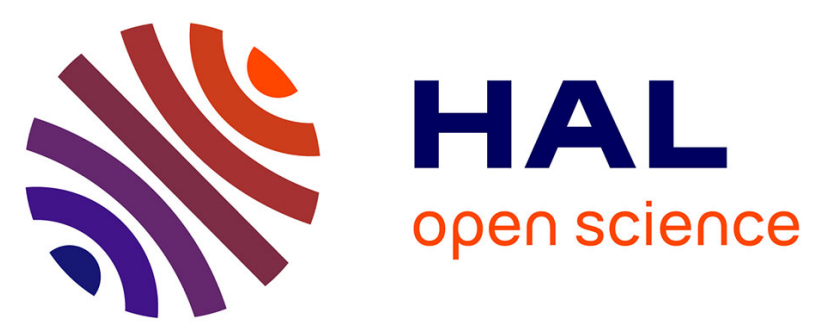

\title{
Cyclophilin A Prevents HIV-1 Restriction in Lymphocytes by Blocking Human TRIM5 $\alpha$ Binding to the Viral Core
}

Anastasia Selyutina, Mirjana Persaud, Lacy Simons, Angel Bulnes-Ramos, Cindy Buffone, Alicia Martinez-Lopez, Viviana Scoca, Francesca Di Nunzio, Joseph Hiatt, Alexander Marson, et al.

\section{To cite this version:}

Anastasia Selyutina, Mirjana Persaud, Lacy Simons, Angel Bulnes-Ramos, Cindy Buffone, et al.. Cyclophilin A Prevents HIV-1 Restriction in Lymphocytes by Blocking Human TRIM5 $\alpha$ Binding to the Viral Core. Cell Reports, 2020, 30 (11), pp.3766-3777.e6. 10.1016/j.celrep.2020.02.100 . pasteur03106108

\section{HAL Id: pasteur-03106108}

\section{https://hal-pasteur.archives-ouvertes.fr/pasteur-03106108}

Submitted on 11 Jan 2021

HAL is a multi-disciplinary open access archive for the deposit and dissemination of scientific research documents, whether they are published or not. The documents may come from teaching and research institutions in France or abroad, or from public or private research centers.
L'archive ouverte pluridisciplinaire HAL, est destinée au dépôt et à la diffusion de documents scientifiques de niveau recherche, publiés ou non, émanant des établissements d'enseignement et de recherche français ou étrangers, des laboratoires publics ou privés.

\section{(ㅇ)(1) $\$$}

Distributed under a Creative Commons Attribution - NonCommercial - NoDerivatives 44.0 


\section{Cell Reports}

\section{Cyclophilin A Prevents HIV-1 Restriction in Lymphocytes by Blocking Human TRIM5 $\alpha$ Binding to the Viral Core}

Graphical Abstract

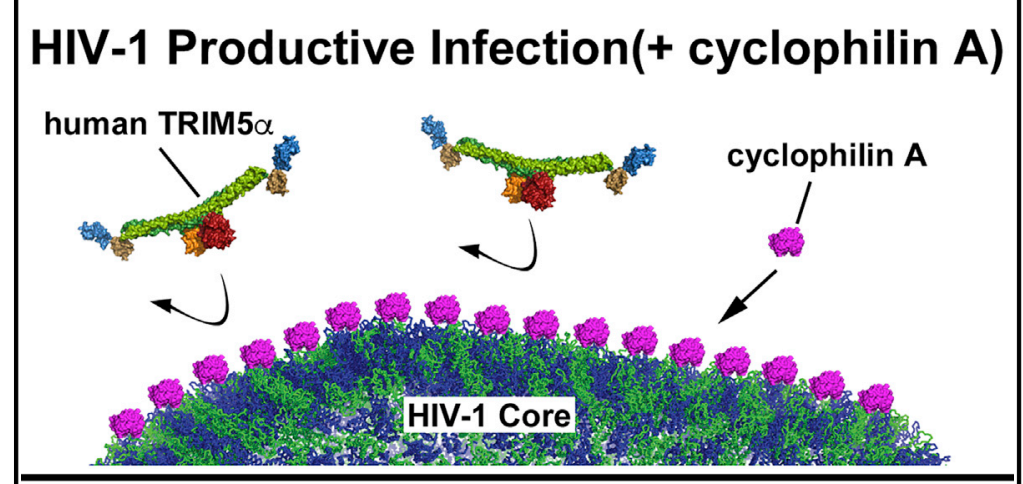

HIV-1 Restriction(- cyclophilin A)

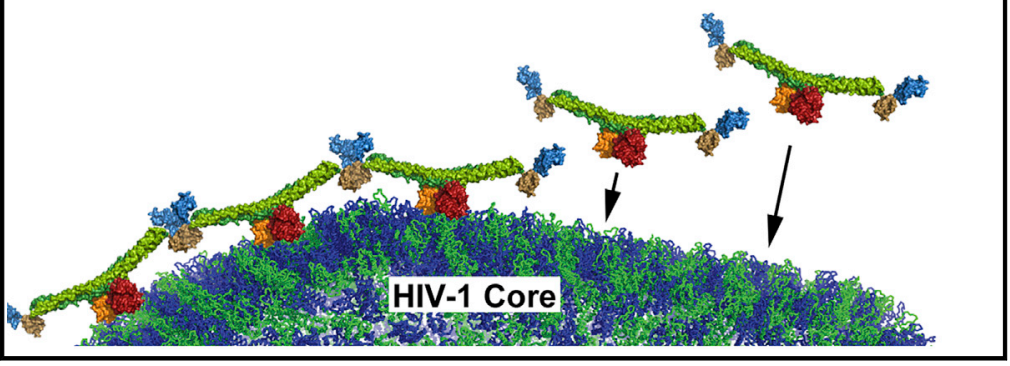

Highlights

- Depletion of cyclophilin A (CypA) expression in $\mathrm{CD}^{+}{ }^{+} \mathrm{T}$ cells blocks HIV-1 infection

- CypA binding to the core prevents HIV-1 restriction by TRIM5 $\alpha$ during $T$ cell infection

- Endogenously expressed TRIM5 $\alpha$ binds to the HIV-1 core and blocks reverse transcription

- Human TRIM5 $\alpha$ binds to HIV-1 cores but not to cores bearing capsid changes A92E/G94D

\section{Authors}

Anastasia Selyutina, Mirjana Persaud, Lacy M. Simons, ..., Nevan J. Krogan, Judd F. Hultquist, Felipe Diaz-Griffero

\section{Correspondence}

felipe.diaz-griffero@einstein.yu.edu

\section{In Brief}

Selyutina et al. show that, during HIV infection, the drug cyclosporine removes cyclophilin A bound to the HIV-1 core, facilitating the interaction between human TRIM5 $\alpha$ and the core. This inhibits infection and explains the mechanism behind the long-standing observation that cyclosporine counteracts HIV. 


\title{
Cyclophilin A Prevents HIV-1 Restriction in Lymphocytes by Blocking Human TRIM5 $\alpha$ Binding to the Viral Core
}

\author{
Anastasia Selyutina, ${ }^{1,9}$ Mirjana Persaud, ${ }^{1,9}$ Lacy M. Simons, ${ }^{5}$ Angel Bulnes-Ramos, ${ }^{1}$ Cindy Buffone, ${ }^{1}$ \\ Alicia Martinez-Lopez, ${ }^{1}$ Viviana Scoca, ${ }^{2}$ Francesca Di Nunzio, ${ }^{2}$ Joseph Hiatt, ${ }^{3,4}$ Alexander Marson, ${ }^{6,7,8}$ Nevan J. Krogan, ${ }^{3,4}$ \\ Judd F. Hultquist, ${ }^{5}$ and Felipe Diaz-Griffero ${ }^{1,10, *}$ \\ ${ }_{1}^{1}$ Department of Microbiology and Immunology, Albert Einstein College of Medicine, Bronx, NY 10461, USA \\ ${ }^{2}$ Molecular Virology and Vaccinology Unit, CNRS UMR 3569, Department of Virology, Institut Pasteur, Paris, France \\ ${ }^{3}$ Department of Cellular and Molecular Pharmacology, Quantitative Biosciences Institute, QBI, University of California, San Francisco, San \\ Francisco, CA 94158, USA \\ 4J. David Gladstone Institutes, San Francisco, CA 94158, USA \\ ${ }^{5}$ Division of Infectious Diseases, Northwestern University Feinberg School of Medicine, Chicago, IL 60611, USA \\ ${ }^{6}$ Department of Medicine and Department of Microbiology and Immunology, Diabetes Center, University of California, San Francisco, San \\ Francisco, CA 94143, USA \\ ${ }^{7}$ Innovative Genomics Institute, University of California, Berkeley, CA 94720, USA \\ ${ }^{8}$ Chan Zuckerberg Biohub, San Francisco, CA 94158, USA \\ ${ }^{9}$ These authors contributed equally to this work \\ ${ }^{10}$ Lead Contact \\ ${ }^{*}$ Correspondence: felipe.diaz-griffero@einstein.yu.edu \\ https://doi.org/10.1016/j.celrep.2020.02.100
}

\section{SUMMARY}

Disruption of cyclophilin A (CурА)-capsid interactions affects HIV-1 replication in human lymphocytes. To understand this mechanism, we utilize human Jurkat cells, peripheral blood mononuclear cells (PBMCs), and $\mathrm{CD}^{+} \mathrm{T}$ cells. Our results show that inhibition of HIV-1 infection caused by disrupting CypA-capsid interactions is dependent on human tripartite motif $5 \alpha$ (TRIM5 $\alpha_{\text {hu }}$ ), showing that TRI$\mathrm{M} 5 \alpha_{\text {hu }}$ restricts HIV-1 in CD4 ${ }^{+} \mathrm{T}$ cells. Accordingly, depletion of TRIM5 $\alpha_{\mathrm{hu}}$ in $\mathrm{CD} 4^{+} \mathrm{T}$ cells rescues HIV1 that fail to interact with CypA, such as HIV-1P90A. We found that TRIM5 $\alpha_{\text {hu }}$ binds to the HIV-1 core. Disruption of CypA-capsid interactions fail to affect HIV-1-A92E/G94D infection, correlating with the loss of TRIM5 $\alpha_{\text {hu }}$ binding to HIV-1-A92E/G94D cores. Disruption of CypA-capsid interactions in primary cells has a greater inhibitory effect on HIV-1 when compared to Jurkat cells. Consistent with TRIM5 $\alpha$ restriction, disruption of CypA-capsid interactions in $\mathrm{CD}^{+} \mathrm{T}$ cells inhibits reverse transcription. Overall, our results reveal that CypA binding to the core protects HIV-1 from TRIM5 $\alpha_{\text {hu }}$ restriction.

\section{INTRODUCTION}

The early steps of human immunodeficiency virus (HIV-1) replication involve delivery of the viral core into the host cytoplasm. The viral core is a conical structure composed of $\sim 1,500$ monomers of the HIV-1 capsid protein, which protects the viral RNA genome (Pornillos et al., 2009; Sundquist and Hill, 2007). The capsid protein plays a role in uncoating, reverse transcription, and nuclear import. To perform these functions, the capsid protein has been shown to functionally interact with several host dependency factors, including cyclophilin A (CypA) (Luban et al., 1993), Nup153 (Brass et al., 2008; Buffone et al., 2018; Di Nunzio et al., 2013; König et al., 2008; Lee et al., 2010; Matreyek and Engelman, 2011; Matreyek et al., 2013; Zhou et al., 2008), RANBP2 (Di Nunzio et al., 2012; Meehan et al., 2014; Ocwieja et al., 2011), TNPO3 (Brass et al., 2008; Christ et al., 2008; König et al., 2008; Krishnan et al., 2010; Levin et al., 2010; Ocwieja et al., 2011; Thys et al., 2011; Valle-Casuso et al., 2012; Zhou et al., 2008), TNPO1 (Fernandez et al., 2019; Idica et al., 2017), and CPSF6 (Lee et al., 2010). Effective HIV-1 infection may occur only when these factors interact with the HIV-1 core at the appropriate time and in the appropriate order, thus raising the possibility that the initial binding of particular factors may modulate the subsequent binding of other factors.

The interaction of CypA with monomeric HIV-1 capsid was originally reported about 30 years ago (Luban et al., 1993), and it has been well established that this interaction modulates HIV-1 infection (Braaten et al., 1996; Braaten and Luban, 2001; Li et al., 2009; Schaller et al., 2011; Sherry et al., 1998; Sokolskaja et al., 2004; Thali et al., 1994; Towers et al., 2003). Although the ability of CypA to modulate HIV-1 infection is cell-type dependent, it is clear that the disruption of CypA-capsid interactions negatively affects HIV-1 infection of lymphocytes (Braaten and Luban, 2001; Li et al., 2009; Ptak et al., 2008; Sherry et al., 1998; Sokolskaja et al., 2004; Towers et al., 2003; Wainberg et al., 1988; Yin et al., 1998); however, the underlying mechanism remains elusive. This work will focus on the mechanism by which the disruption of CypA-capsid interactions negatively affects HIV-1 infection of lymphocytes. 
To investigate the molecular events that result in a decrease in HIV-1 infection upon disruption of CypA-capsid interactions in lymphocytes, we used Jurkat cells, primary human peripheral blood mononuclear cells (PBMCs), and primary human $\mathrm{CD}^{+}$ $T$ cells as experimental models. Our experiments revealed that inhibition of HIV-1 infection caused by disrupting CypA-capsid interactions is dependent on the expression of human tripartite motif $5 \alpha\left(\right.$ TRIM $\left.5 \alpha_{\text {hu }}\right)$. Depletion of TRIM $5 \alpha_{\text {hu }}$ expression in Jurkat and $\mathrm{CD}^{+} \mathrm{T}$ cells rescued HIV-1 infection of viruses that cannot interact with CypA, such as HIV-1-P90A. These results suggest that TRIM5 $\alpha_{\text {hu }}$ restricts HIV-1 infection upon disruption of CypA-capsid interactions. In agreement, we found that TRIM $5 \alpha_{\text {hu }}$ binds to the HIV-1 core. Interestingly, TRIM $5 \alpha_{\text {hu }}$ does not bind to HIV-1 cores bearing the capsid mutant A92E (HIV-1-A92E) or G94D (HIV-1-G94D). Infection of HIV-1-A92E/ G94D viruses was not affected by disruption of CypA-capsid interactions, which correlates with the loss of TRIM $5 \alpha_{\text {hu }}$ binding to HIV-1 cores bearing the A92E/G94D mutation. These experiments suggest that CypA protects the HIV-1 core from TRIM5 $\alpha_{\text {hu. }}$ Although the infectivity defect observed in Jurkat cells is small, disruption of CypA-interactions in PBMCs and $\mathrm{CD}^{+} \mathrm{T}$ cells causes a major defect in infectivity. In agreement with our hypothesis that CypA protects the core from TRIM $5 \alpha_{\text {hu }}$, infection of PBMCs and CD4 ${ }^{+}$T cells by HIV-1-A92E viruses was insensitive to the disruption of CypA-capsid interactions. Consistent with a block imposed by TRIM $5 \alpha$ proteins, disruption of CypA-capsid interactions in $\mathrm{CD}^{+} \mathrm{T}$ cells dramatically decreased the efficiency of reverse transcription. Overall, our investigations suggest a model in which CypA binding to the HIV-1 core protects the core from the restriction factor TRIM $5 \alpha_{\text {hu. }}$.

\section{RESULTS}

\section{HIV-1 Infection of Jurkat Cells Is Sensitive to \\ Cyclosporin A Treatment}

To understand the role of CypA in HIV-1 infection of CD4 ${ }^{+} \mathrm{T}$ cells, we used the human $T$ cell line Jurkat as an experimental model. Cyclosporin A (CsA) is a molecule that binds to CypA and thus blocks cellular CypA activity. To measure the effect of CsA treatment on HIV-1 infectivity, we infected Jurkat cells with HIV-1 tagged with green fluorescent protein pseudotyped with the vesicular stomatitis virus G (VSV-G) envelope (HIV-1-GFP) in the presence of $10 \mu \mathrm{M}$ CsA. Consistent with results from previous studies (Braaten and Luban, 2001; Hatziioannou et al., 2005; Li et al., 2009; Ptak et al., 2008; Sokolskaja et al., 2004; Towers et al., 2003; Wainberg et al., 1988; Yin et al., 1998), HIV-1-GFP infection of human Jurkat T cells was sensitive to CsA treatment (Figure S1A, top panel). Experiments were repeated multiple times, and the fraction of GFP-positive cells normalized to the dimethyl sulfoxide (DMSO)-treated control is shown in Figure S1A (bottom panel). To further confirm the importance of CypA-capsid interactions in HIV-1 infection, we challenged Jurkat $T$ cells with p24-normalized amounts of HIV-1-P90A-GFP and HIV-1-G89V-GFP, which are mutant versions of HIV-1 that disrupt CypA-capsid interactions (Gamble et al., 1996; Thali et al., 1994). Infection was determined by measuring the percentage of GFP-positive cells $48 \mathrm{~h}$ post-infection. We found that the mutant HIV-1 strains bearing capsid changes that dis- rupted CypA-capsid interactions were less infectious than wild-type HIV-1 (Figure S1B, top panel). Experiments were repeated multiple times, and the fraction of GFP-positive cells normalized to control is shown in Figure S1B (bottom panel). Although Jurkat cells failed to show a dramatic decrease in HIV-1 infectivity as a result of disrupted CypA-capsid interactions, we still used this cell line as a model to mechanistically understand the contribution of CypA to HIV-1 infection.

\section{TRIM5 $\alpha_{\text {hu }}$ Binds to the HIV-1 Capsid}

Previous studies have shown that CypA modulates the ability of rhesus TRIM protein, TRIM5 $\alpha_{\text {rh }}$, to restrict HIV-1 infection (Berthoux et al., 2005; Burse et al., 2017; Keckesova et al., 2006; Lin and Emerman, 2008; Stremlau et al., 2006b), which is not surprising because both proteins interact with the HIV-1 core. One model is that TRIM5 $\alpha_{\text {rh }}$ cages the HIV- 1 core using cooperative binding during infection (Diaz-Griffero et al., 2009; Ganser-Pornillos et al., 2011; Stremlau et al., 2006a). Because both CypA and TRIM5 $\alpha_{\mathrm{rh}}$ bind to the HIV-1 core, it is possible that CypA modulates the binding of TRIM $5 \alpha_{r h}$ to the HIV-1 core or vice versa.

More recent studies have suggested that TRIM $5 \alpha_{\text {hu }}$ blocks HIV-1 infection (Jimenez-Guardeño et al., 2019; OhAinle et al., 2018), possibly by binding to the HIV-1 core. Therefore, we tested the ability of TRIM $5 \alpha_{\text {hu }}$ to bind to the HIV-1 core using our new capsid-binding assay that incorporates washing steps (Selyutina et al., 2018). This new capsid-binding assay has been extensively validated by using different capsid binding proteins (Selyutina et al., 2018). This capsid-binding assay utilizes capsid tubes that are stabilized by disulfide bonds, providing the necessary stability to sustain washing steps, which were not possible when using the capsid-binding assay that utilized in vitro assembled capsid-nucleocapsid (CA-NC) tubes. Using this new assay, we found that TRIM $5 \alpha_{\text {hu }}$ binds to the HIV-1 core (Figure 1A). TRIM5 $\alpha_{\text {hu }}$ showed a stronger interaction with the HIV-1 core when compared with TRIM5 $\alpha_{\text {rh }}$ (Figure 1A). To further test these results, we compared TRIM $5 \alpha_{\mathrm{hu}}$ and TRIM $5 \alpha_{\mathrm{rh}}$ binding to in vitro assembled HIV-1 CA-NC complexes (Figure 1B). Our results showed that TRIM5 $\alpha_{\text {hu }}$ interacts with the HIV-1 CA assembled tubes, suggesting that TRIM $5 \alpha_{\text {hu }}$ interacts with the HIV-1 core. One possibility is that CypA modulates the ability of TRIM $5 \alpha_{\text {hu }}$ to interact with the HIV-1 core in lymphocytes.

TRIM5 $\alpha_{\text {hu }}$ Expression Is Necessary for the Inhibition of HIV-1 Infection Mediated by the Disruption of CypACapsid Interactions

Because of the ability of TRIM $5 \alpha_{\text {hu }}$ to bind to the HIV-1 core, we tested whether TRIM5 $\alpha_{\mathrm{hu}}$ is involved in the blocking of HIV-1 infection mediated by the disruption of CypA-capsid interactions. For this purpose, we achieved knockdown (KD) of TRI$M 5 \alpha_{\mathrm{hu}}$ expression in Jurkat cells using a specific short hairpin RNA (shRNA) against TRIM5 $\alpha_{\text {hu }}$ (Figure 2A), as described in STAR Methods. To test for TRIM5 $\alpha_{h u}$ function, we challenged different sets of TRIM $5 \alpha_{\text {hu }}$ KD cells with increasing amounts of $\mathrm{N}$-tropic murine leukemia virus GFP (N-MLV-GFP), which is restricted by TRIM $5 \alpha_{\text {hu }}$. We found that Jurkat TRIM $5 \alpha_{\text {hu }}-$ KD cells were susceptible to N-MLV infection (Figure S2), whereas, in 
A

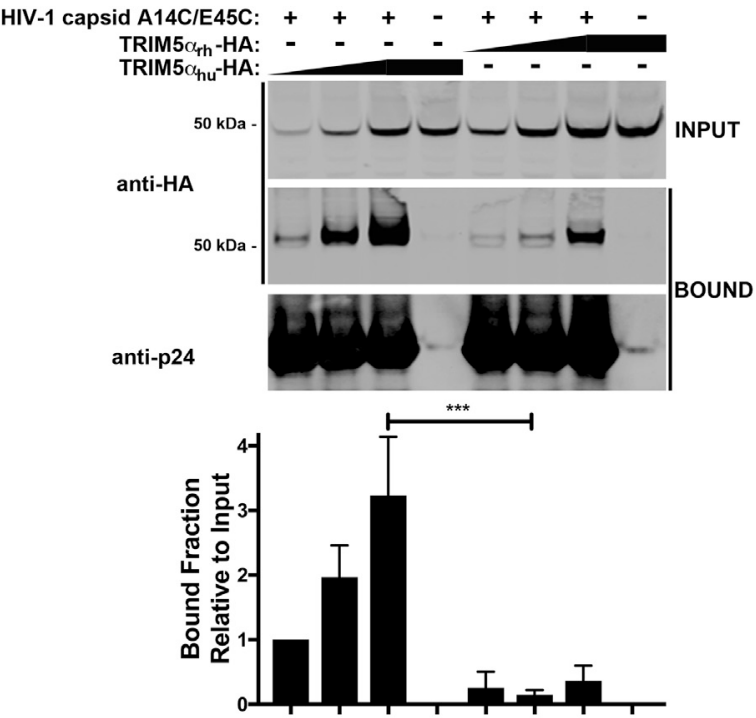

B

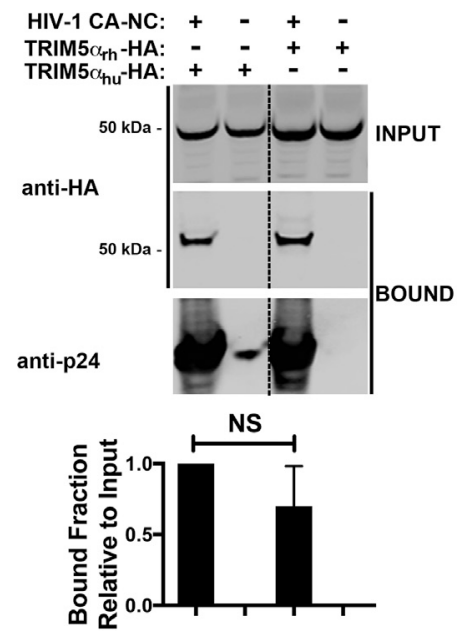

Figure 1. TRIM $5 \alpha_{\text {hu }}$ Binds to the HIV-1 Core

Human 293T cells were transfected with plasmids expressing the wild-type human TRIM $5 \alpha$ tagged with an HA epitope (TRIM $5 \alpha_{\text {hu }}-\mathrm{HA}$ ).

(A) $24 \mathrm{~h}$ post-transfection, cells were lysed in capsid binding buffer (CBB), as described in STAR Methods. Inputs containing different amounts of TRIM5 $\alpha_{\mathrm{hu}}$ were prepared (INPUT). Cell extracts containing different amounts of TRIM5 $\alpha_{\mathrm{hu}}-\mathrm{HA}$ were mixed with $20 \mu \mathrm{L}$ of stabilized HIV-1 capsid tubes $(5 \mathrm{mg} /$ $\mathrm{mL}$ ) and incubated for $1 \mathrm{~h}$ at room temperature. Stabilized HIV-1 capsid tubes were collected by centrifugation and washed twice using CBB.

(B) Alternatively, cells were lysed in CBB with DTT, and a fraction of the cell lysate was stored (INPUT). Cell extracts were mixed with $5 \mu \mathrm{L}$ of capsidnucleocapsid (CA-NC) particles assembled in vitro and incubated for $1 \mathrm{~h}$ at room temperature. Subsequently, the mixture was spun through a $70 \%$ sucrose cushion. Pellets were resuspended in $1 \times$ Laemmli buffer (BOUND). INPUT and BOUND fractions were analyzed by western blotting using anti-HA and anti-p24 antibodies. As control, similar experiments were performed using the capsid binder, rhesus TRIM5 $\alpha$ tagged with an HA epitope (TRIM5 $\alpha_{\mathrm{rh}}-\mathrm{HA}$ ). Experiments were repeated six times and a representative experiment is shown. The bound fraction relative to input for six independent experiments with standard deviations is shown. ${ }^{* \star *} p<0.0005$ as determined by the unpaired $t$ test.
shRNA control cells, N-MLV-GFP infection was blocked (Figure S2). As a control, we also showed that TRIM5 $\alpha_{\text {hu }}$ KD cells were susceptible to B-tropic murine leukemia virus GFP (BMLV-GFP), which is not restricted by TRIM5 $\alpha_{\text {hu }}$ (Figure S2). These results confirmed that KD of TRIM $5 \alpha_{\text {hu }}$ expression was successfully achieved.

Next, we assessed the infection phenotype observed in Jurkat TRIM5 $\alpha_{\text {hu }}$ KD cells when CypA-capsid interactions are disrupted (Figures 2B and S2B). TRIM5 $\alpha_{\text {hu }}$ KD cells treated with CsA did not show marked inhibition of HIV-1-GFP infection compared with control cells (Figures $2 \mathrm{~B}$ and $\mathrm{S} 2 \mathrm{~B}$ ), suggesting that TRIM5 $\alpha_{\mathrm{hu}}$ is involved in the inhibition of viral infection observed in cells that CypA-capsid interactions are disrupted.

HIV-1-P90A-GFP is a mutant form of HIV-1 in which CypAcapsid interactions are disrupted during infection. We tested whether HIV-1-P90A-GFP infection was inhibited in TRIM5 $\alpha_{\text {hu }}$ $\mathrm{KD}$ Jurkat cells. As shown in Figures $2 \mathrm{C}$ and $\mathrm{S} 2 \mathrm{~B}$, we found that HIV-1-P90A-GFP infection was not inhibited in TRIM5 $\alpha_{\text {hu }}$ KD cells compared with control cells. This result supports our hypothesis that expression of TRIM5 $\alpha_{h u}$ is important for the infection phenotype observed when CypA-capsid interactions are disrupted in lymphocytes. It is possible that CypA prevents the binding of TRIM5 $\alpha_{\mathrm{hu}}$ to the HIV-1 core via steric hindrance, thus protecting the core from the restriction factor during the early steps of infection.

\section{CypA Prevents the Interaction of TRIM5 $\alpha_{\text {hu }}$ with the HIV-1 Core}

To test whether CypA modulates the binding of TRIM5 $\alpha_{\text {hu }}$ to the HIV-1 core, we analyzed the binding of TRIM $5 \alpha_{\text {hu }}$ to the HIV-1 core in the presence of CsA, which binds to endogenously expressed CypA in cellular extracts and prevents CypA binding to the HIV-1 core. As shown in Figure 3A, TRIM5 $\alpha_{\text {hu }}$ binding to the HIV-1 core increased 3- to 4-fold in the presence of CsA. We also found that the binding of TRIM5 $\alpha_{\text {hu }}$ to mutant P90A HIV-1 cores was 5- to 6-fold higher than that of wild-type HIV-1 cores (Figure $3 A$ ) in the absence of CsA. These results suggest that CypA prevents the binding of TRIM $5 \alpha_{h u}$ to the HIV-1 core during infection. It is possible that CypA and TRIM5 $\alpha_{\text {hu }}$ compete with each other to interact with the incoming core. To test this hypothesis, we investigated whether the addition of exogenous CypA decreased TRIM5 $\alpha_{\text {hu }}$ binding to the HIV-1 core. For this purpose, we assessed the ability of TRIM $5 \alpha_{\mathrm{hu}}$ from cellular extracts to bind to the HIV-1 core in the presence of $10 \mu \mathrm{g}$ of recombinant CypA protein. We found that the addition of recombinant CypA significantly decreased the binding of TRIM $5 \alpha_{h u}$ to the HIV-1 core (Figure 3B). As expected, recombinant CypA did not affect the binding of TRIM $5 \alpha_{\mathrm{hu}}$ to HIV-1 cores bearing the P90A mutation. Overall, these results suggest that CypA protects the core from the restriction factor TRIM $5 \alpha_{\text {hu. }}$.

\section{Mutant HIV-1 Strains that Are Impaired for} Capsid-TRIM5 $\alpha_{\text {hu }}$ Interactions Are Insensitive to CsA Treatment

Previous studies have shown that infection of Jurkat cells by the HIV-1 strain bearing the capsid mutation A92E or G94D 
A

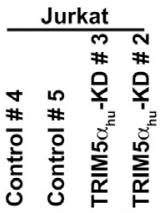

Anti-TRIM5 $\alpha$

Anti-GAPD

B
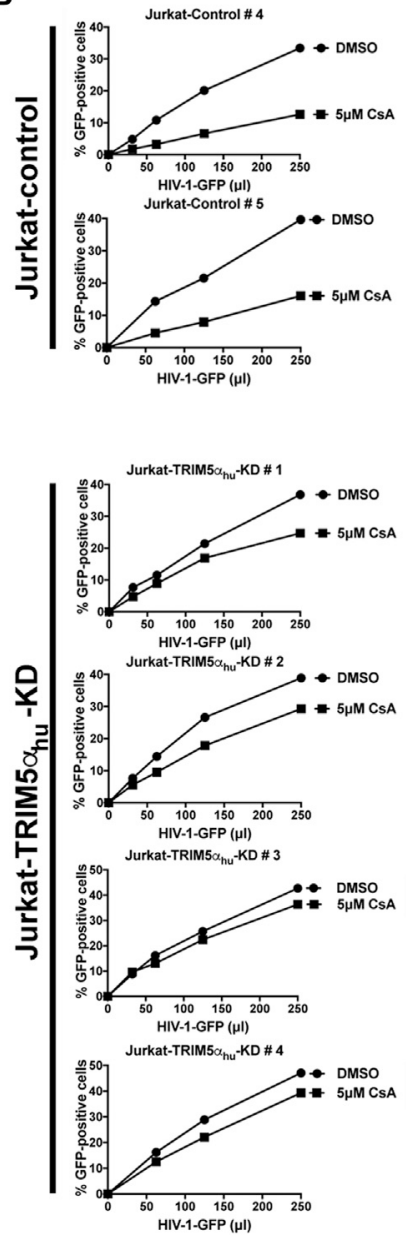

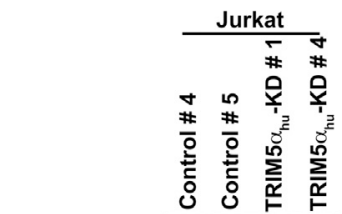

Anti-TRIM5 $\alpha_{\mathrm{h}}$

Anti-GAPDH

C

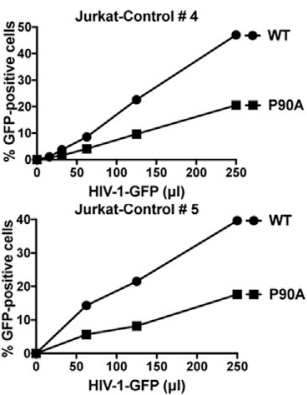

Jurkat-TRIM5 $\alpha_{h u}-K D \# 1$

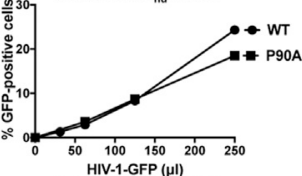

Jurkat-TRIM5 $\alpha,-K D \# 2$
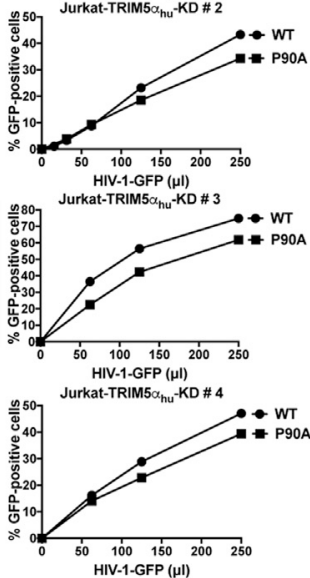

Figure 2. Expression of TRIM5 $\alpha_{\text {hu }}$ Is Necessary for the Inhibition of HIV-1 Infection Caused by the Disruption of CypA-Capsid Interactions

(A) Human Jurkat cells stably expressing a specific shRNA against TRIM5 $\alpha_{\text {hu }}$ (Jurkat-TRIM5 $\alpha_{\mathrm{hu}}-\mathrm{KD} \# 1-\# 4$ ) or the empty vector (Jurkat-Control \#4 and \#5) were analyzed for endogenous expression of TRIM $5 \alpha_{\mathrm{hu}}$ by western blotting using antibodies against TRIM5 $\alpha_{\text {hu. }}$. Expression of GAPDH was used as a loading control.

(B) Jurkat-TRIM5 $\alpha_{\mathrm{hu}}-\mathrm{KD}$ and Jurkat-control cells were challenged with increasing amounts of HIV-1 expressing GFP as a reporter of infection (HIV-1GFP) in the presence of $5 \mu \mathrm{M}$ cyclosporin A (CsA). As a control, similar experiments were performed using DMSO.

(C) Jurkat-TRIM5 $\alpha_{\mathrm{hu}}-\mathrm{KD}$ and Jurkat-control cells were challenged with increasing amounts of p24-normalized HIV-1-GFP or HIV-1-P90A-GFP. Infection was determined at $48 \mathrm{~h}$ post-challenge by measuring the percentage of GFP-positive cells using a flow cytometer.

was less sensitive to CsA treatment when compared with wildtype HIV-1 (Hatziioannou et al., 2005; Sokolskaja et al., 2004). Consistent with these findings, we observed that HIV-1-A92EGFP infection of Jurkat cells was insensitive to CsA treatment (Figure S3). This insensitivity may occur due to HIV-1-A92EGFP inability to interact with TRIM $5 \alpha_{\text {hu }}$. To explore this possibility, we tested whether TRIM5 $\alpha_{\text {hu }}$ interacts with HIV-1 cores containing the A92E mutation. We found that TRIM5 $\alpha_{\text {hu }}$ did not interact with mutant HIV-1 cores bearing the capsid change A92E (Figure 3C). We observed similar results using the capsid mutant G94D (Figure 3C), which showed a similar pattern of infectivity when compared to HIV-1-A92E-GFP viruses. As a control, we showed that the binding of TRIM $5 \alpha_{h u}$ to wild-type HIV-1 cores increased when CsA was added (Figure 3C). Overall, these results indicate that $\operatorname{TRIM} 5 \alpha_{\text {hu }}$ does not bind to mutant HIV-1 capsids bearing the change A92E or G94D, which may explain the reason that CsA treatment does not affect the infection of Jurkat cells by HIV-1-A92E-GFP or HIV-1-G94DGFP viruses.

\section{Endogenously Expressed TRIM5 $\alpha_{\text {hu }}$ Binds to the HIV-1 Capsid}

Next, we tested whether the endogenously expressed TRIM $5 \alpha_{\text {hu }}$ binds to the HIV-1 capsid. As shown in Figure 3D, endogenously expressed TRIM $5 \alpha_{\text {hu }}$ from cellular extracts derived from HT1080 cells binds to stabilized HIV-1 capsid tubes. This showed the ability of endogenously expressed TRIM $5 \alpha_{\text {hu }}$ to bind to HIV-1 capsid. As a control, we utilized HT1080 cells that were knocked out for expression of TRIM $5 \alpha_{h u}\left(H T 1080-T R I M 5 \alpha_{h u}-K O\right)$. In agreement with our previous results, the use of CsA increased the binding of endogenously expressed TRIM $5 \alpha_{\mathrm{hu}}$ to stabilized HIV-1 capsid tubes (Figure 3D). Furthermore, endogenously expressed TRIM5 $\alpha_{\text {hu }}$ also bound to stabilized HIV-1 capsid tubes bearing the P90A mutation (Figure 3E).

\section{CypA-Capsid Interactions Are Required for HIV-1} Infection of Human PBMCs and CD4 ${ }^{+} \mathrm{T}$ Cells To understand the role of CypA in HIV-1 infection of human primary cells, we challenged PBMCs and $\mathrm{CD}^{+} \mathrm{T}$ cells from different donors with HIV-1-GFP in the presence of increasing concentrations of CsA, which prevents the binding of CypA to HIV-1 capsid (Diaz-Griffero et al., 2006; Luban et al., 1993). As shown in Figure S4A, CsA treatment inhibited HIV-1 infection in PBMCs. Similarly, CsA inhibited HIV-1-GFP infection of human primary $\mathrm{CD}^{+} \mathrm{T}$ cells (Figure $\mathrm{S} 4 \mathrm{~B}$ ). This result suggests that CypA-capsid interactions are required for HIV-1-GFP infection of human PBMCs and $\mathrm{CD} 4^{+} \mathrm{T}$ cells. To further corroborate these findings, we challenged human PBMCs and $\mathrm{CD} 4^{+} \mathrm{T}$ cells with increasing amounts of HIV-1-GFP particles bearing the capsid mutations P90A and G89V, both of which prevent CypA-capsid interactions (Gamble et al., 1996; Thali et al., 1994). Infection was determined by measuring the percentage of GFP-positive cells at $72 \mathrm{~h}$ post-infection. Wild-type and mutant HIV-1-GFP

Each experiment was repeated at least three times and a representative experiment is shown. Statistical analysis of these experiments is shown in Figure S2B. 
A HIV-1 capsid A14C/E45C: WT WT - P90A P90A -
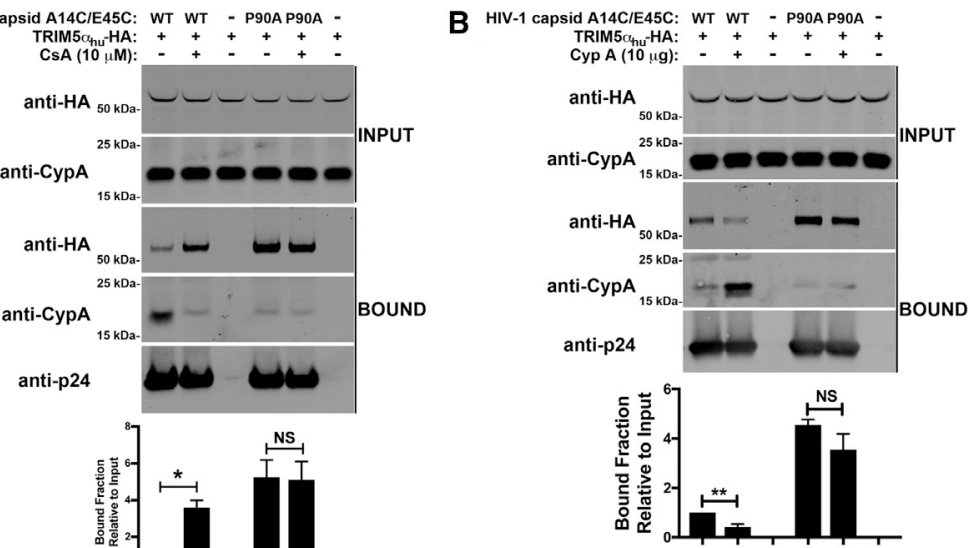
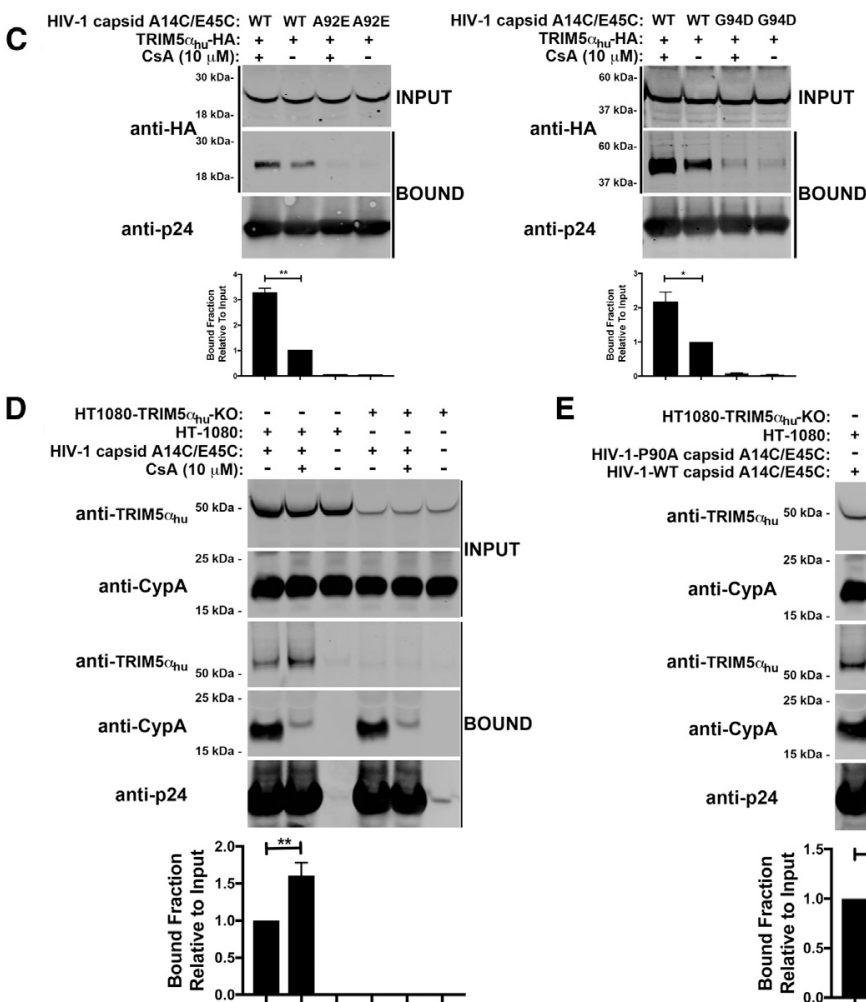

E
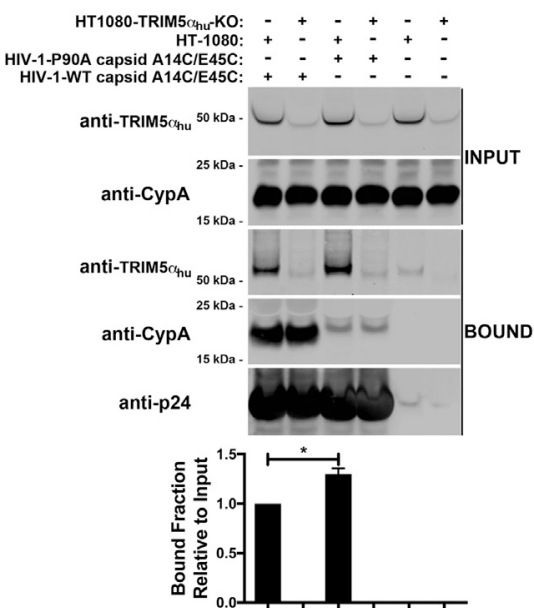

Figure 3. CypA Prevents the Binding of TRIM5 $\alpha_{\text {hu }}$ to the HIV-1 Core

(A-C) Human 293T cells were transfected with plasmids expressing TRIM $5 \alpha_{\mathrm{hu}}-\mathrm{HA} .24 \mathrm{~h}$ posttransfection, cells were lysed in capsid binding buffer (CBB) (INPUT). Cell extracts containing TRIM $5 \alpha_{\mathrm{hu}}-\mathrm{HA}$ were mixed with $20 \mu \mathrm{L}$ of stabilized wild-type or P90A HIV-1 capsid tubes $(5 \mathrm{mg} / \mathrm{mL})$ in the presence of $10 \mu \mathrm{M}$ CsA (A) or $10 \mu \mathrm{g}$ recombinant CypA (B). (C) Cell extracts containing TRIM $5 \alpha_{h u}-H A$ were mixed with $20 \mu \mathrm{L}$ of stabilized wild-type, A92E, or G94D HIV-1 capsid tubes $(5 \mathrm{mg} / \mathrm{mL})$ in the presence of $10 \mu \mathrm{M} \mathrm{CsA}$.

(D and E) HT1080 cells (control or TRIM5 $\alpha_{\text {hu }}$ CRISPR/Cas9 knockout) were lysed in capsid binding buffer (CBB) (INPUT). Cell extracts were mixed with either $20 \mu \mathrm{L}$ of stabilized wild-type HIV-1 capsid tubes $(5 \mathrm{mg} / \mathrm{mL})$ in the presence of $10 \mu \mathrm{M}$ CsA (D) or $20 \mu \mathrm{L}$ of stabilized wild-type or P90A HIV-1 capsid tubes $(5 \mathrm{mg} / \mathrm{mL})(E)$. Mixtures were incubated for $1 \mathrm{~h}$ at room temperature. Stabilized HIV-1 capsid tubes were collected by centrifugation and washed twice using CBB. Pellets were resuspended in $1 \times$ Laemmli buffer (BOUND). INPUT and BOUND fractions were analyzed by western blotting using anti-HA, antiTRIM5 $\alpha_{\text {hu }}$, anti-CypA, and anti-p24 antibodies. Experiments were repeated three times and a representative experiment is shown. The bound fraction relative to input for three independent experiments with standard deviation is shown. ${ }^{*} p<$ $0.005,{ }^{* *} \mathrm{p}<0.001$, ns indicates not significant as determined by the unpaired $t$ test.

disruption of CypA-capsid interaction is detrimental for HIV-1 infection of PBMCs and $\mathrm{CD}^{+} \mathrm{T}$ cells.

\section{Disruption of HIV-1 Binding to} TRIM5 $\alpha_{\text {hu }}$ Does Not Affect Viral Infection in Human PBMCs and CD4 $^{+}$T Cells

Mutant HIV-1 bearing the capsid change A92E or G94D lacks the ability to interact with TRIM5 $\alpha_{\text {hu }}$ (Figure $3 \mathrm{C}$ ). In order to study the role of TRIM $5 \alpha_{h u}$ during viral infection, we examined the ability of HIV-

viruses were normalized by quantifying the levels of p24. We found that HIV-1-P90A-GFP and HIV-1-G89V-GFP were unable to infect human PBMCs or $\mathrm{CD}^{+}{ }^{+} \mathrm{T}$ cells (Figures $4 \mathrm{~A}$ and S5). Although these experiments were performed in PBMCs and $\mathrm{CD}^{+} \mathrm{T}$ cells obtained from six different donors, all of which showed similar results, we have only shown sample results obtained from three donors. Our results suggest that CypA-capsid interactions are required for HIV-1 infection in human primary PBMCs and CD4 ${ }^{+}$T cells. Importantly, the lack of CypA binding appeared to have a stronger effect on HIV-1 infection in primary human lymphocytes when compared with that of Jurkat cells (Figure 2), thus indicating that CypA is crucial for HIV-1 infection of human primary cells. Overall, these results suggest that the
1-A92E-GFP and HIV-1-G94D-GFP to infect CD4 ${ }^{+} \mathrm{T}$ cells (Figures $4 \mathrm{~B}$ and $4 \mathrm{C}$ ). Consistent with results observed in Jurkat cells, infection levels by the mutant viruses were slightly affected when compared to that of wild-type HIV-1-GFP in primary human $\mathrm{CD}^{+} \mathrm{T}$ cells (Figures $4 \mathrm{~B}$ and $4 \mathrm{C}$ ). As a control, we also challenged $\mathrm{CD}^{+}{ }^{+} \mathrm{T}$ cells with increasing concentrations of HIV-1P90A-GFP, an HIV-1 mutant that is completely inhibited in $\mathrm{CD}^{+} \mathrm{T}$ cells (Figures $4 \mathrm{~B}$ and $4 \mathrm{C}$ ). Consistent with our previous binding experiments, these experiments suggest that infection of $\mathrm{CD}^{+} \mathrm{T}$ cells by HIV-1-A92E-GFP or HIV-1-G94D-GFP was not affected by TRIM $5 \alpha_{\mathrm{hu}}$, which correlated with the inability of TRIM $5 \alpha_{\text {hu }}$ to bind to HIV-1 cores bearing the mutation A92E or G94D. We also demonstrate that CsA does not affect the ability 
A
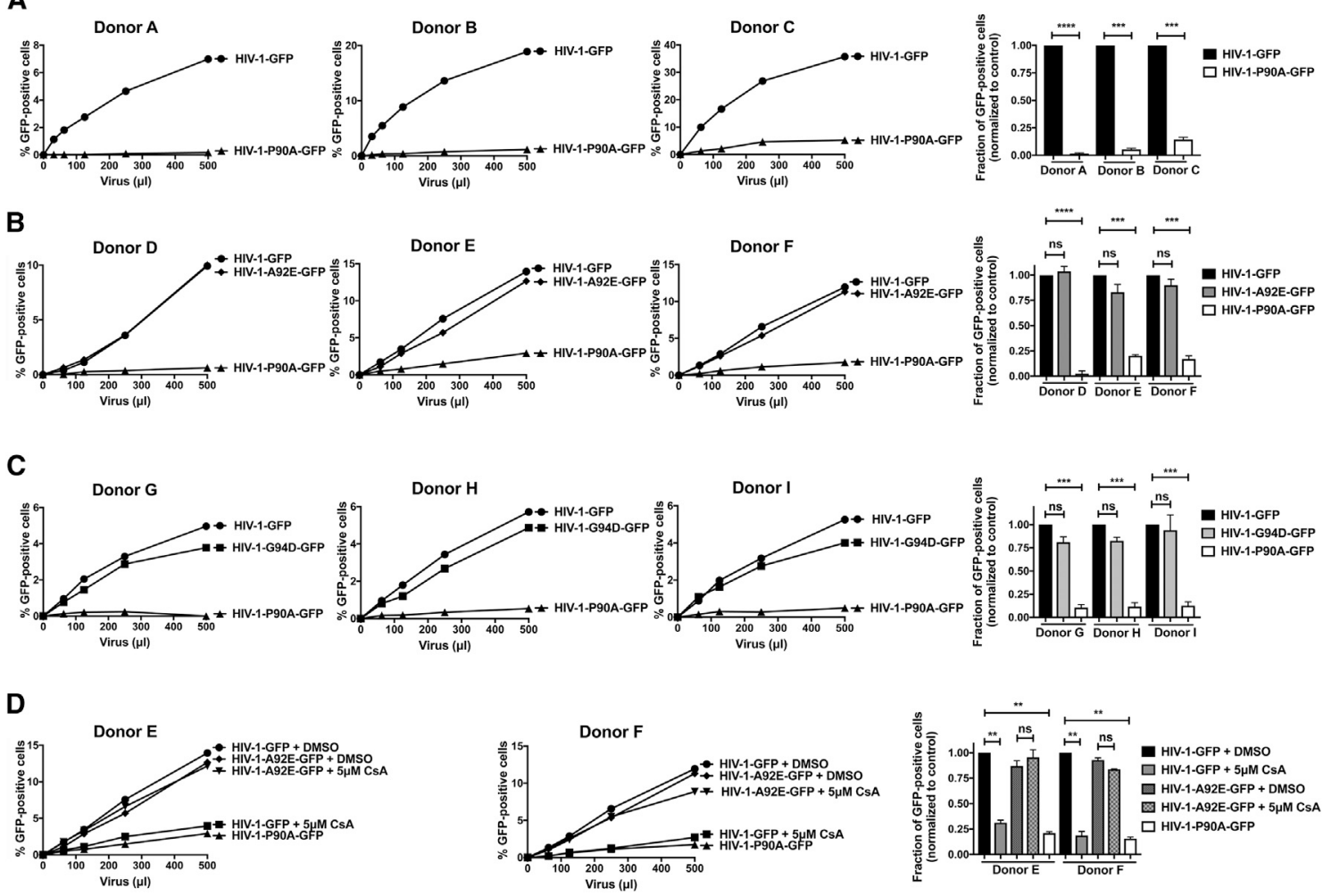

Figure 4. CypA-Capsid Interactions Are Required for HIV-1 Infection of Human CD4 ${ }^{+} \mathrm{T}_{\text {Cells }}$

(A-C) Purified CD4 ${ }^{+}$T cells were challenged with increasing amounts of p24-normalized HIV-1-GFP or HIV-1-P90A-GFP (A) and either HIV-1-A92E-GFP (B) or HIV-1-G94D-GFP (C). Alternatively, purified CD4 ${ }^{+}$T cells were challenged with increasing amounts of p24-normalized HIV-1-GFP or HIV-1-A92E-GFP in the presence of $5 \mu \mathrm{M}$ cyclosporin $\mathrm{A}(\mathrm{CsA})$.

(D) DMSO was used as control. Infection was determined at $72 \mathrm{~h}$ post-challenge by measuring the percentage of GFP-positive cells.

Experiments were repeated three times per donor and a representative experiment is shown. The results of three independent experiments with standard deviation are shown; statistical analysis was performed using an intermediate value taken from the infection curves. ${ }^{* *} p<0.001,{ }^{* \star *} p<0.0005$, ${ }^{* \star * *} p<0.0001$, ns indicates not significant as determined by the unpaired $t$ test.

of HIV-1-A92E-GFP viruses to infect human primary CD4 ${ }^{+} \mathrm{T}$ cells (Figure 4D), suggesting that HIV-1-A92E-GFP viruses are insensitive to TRIM5 $\alpha_{\text {hu. }}$

\section{Depletion of CypA Expression in Human CD4 ${ }^{+} \mathrm{T}$ Cells Inhibits HIV-1 Infection}

We have previously shown indirectly that CypA-capsid interactions are important for HIV-1 infection. To directly test the role of CypA in viral infection, we challenged CypA knockout $\mathrm{CD}^{+} \mathrm{T}$ cells with HIV-1-GFP (VSV-G pseudotyped virus) or HIV-1 ${ }_{\text {NL4-3 }}$-GFP (replication competent virus). To create CypA knockouts, $\mathrm{CD}^{+}{ }^{+} \mathrm{T}$ cells were separately electroporated with CRISPR/Cas9 complexes containing five different guides against СypA (CypA-KO\#1-5). Expression of CypA was analyzed by western blotting using anti-CypA antibodies at 3 days postelectroporation. As shown in Figure $5 \mathrm{~A}$, all five guides were able to eliminate the expression of CypA. The CypA knockout cells were then challenged with HIV-1-GFP (Figure 5B) or replica-

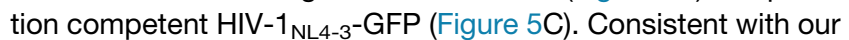
previous results, human $\mathrm{CD} 4^{+} \mathrm{T}$ cells depleted for CypA expression were resistant to HIV-1 infection. As a control, we used a
CRISPR/Cas9 complex containing a non-targeting RNA guide (Figures 5B and 5C). As an additional control in experiments us-

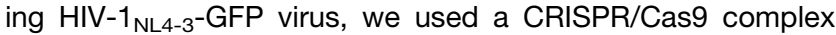
containing an RNA guide for CXCR4, which completely inhibits infection of the replication-competent virus HIV-1 NL4-3 $_{3}$-GFP (Figure $5 \mathrm{C}$ ). These results demonstrate that CypA expression is essential for HIV-1 infection of human primary $\mathrm{CD} 4^{+} \mathrm{T}$ cells.

\section{Depletion of TRIM5 $\alpha_{\text {hu }}$ Expression in Human CD4 ${ }^{+} \mathbf{T}$} Cells Rescues Infection by HIV-1-P90A Viruses

Our results show that TRIM5 $\alpha_{\text {hu }}$ does not interact with $\mathrm{A} 92 \mathrm{E}$ cores. In addition, we show that HIV-1-A92E viruses do not exhibit a replication defect in primary $C D 4^{+} \mathrm{T}$ cells in the absence or presence of CsA. Altogether, these results suggest that TRIM5 $\alpha_{\text {hu }}$ blocks HIV-1 replication in primary CD $4^{+}$T cells where CypA-capsid interactions have been disrupted. To test whether TRIM $5 \alpha_{\mathrm{hu}}$ blocks the infection of viruses that do not interact with CypA, we challenged TRIM $5 \alpha_{\text {hu }}$ knockout $\mathrm{CD} 4^{+} \mathrm{T}$ cells with increasing amounts of HIV-1-P90A viruses. As shown in Figure 6A, gRNA\#6 and gRNA\#7 efficiently depleted TRIM5 $\alpha_{\text {hu }}$ expression in $\mathrm{CD}^{+}{ }^{+} \mathrm{T}$ cells. Consistent with our hypothesis, 
A
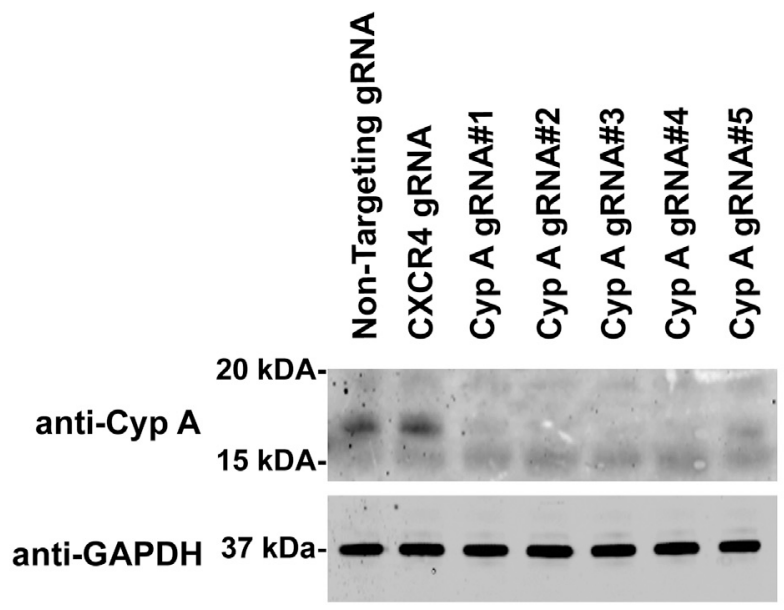

\section{Donor A}

B

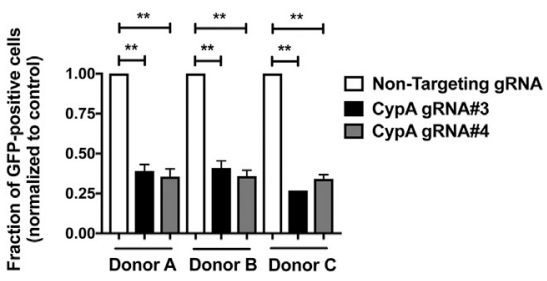

C

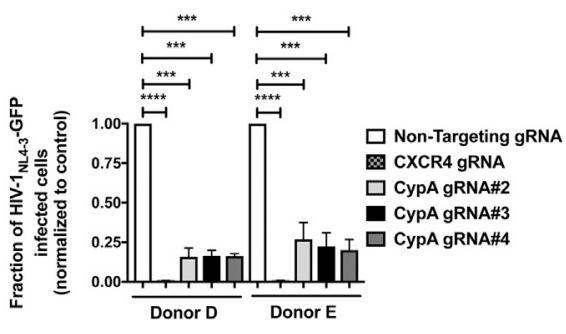

Figure 5. Depletion of CypA Expression in Human CD4 ${ }^{+}$T Cells Inhibits HIV-1 Infection (A) Human primary $C D 4^{+} \mathrm{T}$ cells from two different donors were knocked out for CypA expression using the CRISPR/Cas9 system, as described in STAR Methods. Briefly, $\mathrm{CD} 4^{+} \mathrm{T}$ cells were electroporated using five different guide RNAs (gRNAs) against CypA (gRNA\#1-\#5) together with the Cas9 protein. At $72 \mathrm{~h}$ post-electroporation, endogenous expression of CypA in $\mathrm{CD}^{+} \mathrm{T}$ was analyzed by western blotting using antibodies against CypA. For controls, we electroporated a gRNA against CXCR4 and a non-targeting gRNA. Expression of GAPDH was used as a loading control. Similar results were obtained using three different donors and a representative blot is shown.

(B and C) Human primary $\mathrm{CD} 4^{+} \mathrm{T}$ cells depleted for CypA expression were challenged with HIV-1-GFP pseudotyped with the VSV-G envelope (B) or with a replication-competent HIV-1 expressing GFP as a reporter of infection (HIV-1 ${ }_{\text {NL4-3 }}$-GFP) (C). Infection was determined at $72 \mathrm{~h}$ post-infection by measuring the percentage of GFP-positive cells. Experiments were performed in triplicates and results for three (B) or two (C) different donors with standard deviation are shown. ${ }^{* *} \mathrm{p}<0.001,{ }^{* * *} \mathrm{p}<$ $0.0005,{ }^{* \star \star *} p<0.0001$ determined by the unpaired t test.

CypA-capsid interactions were important for HIV-1 reverse transcription in $\mathrm{CD}^{+}$ T cells. As a control, we used Nevirapine (Nev), which inhibits reverse transcription (Figure S6B). For nuclear import, we depletion of TRIM5 $\alpha_{\text {hu }}$ expression completely rescued infection of HIV-1-P90A viruses (Figure 6B). Considering that HIV-1P90A-GFP does not bind CypA protein but does bind TRIM5 $\alpha_{\text {hu, }}$, these results demonstrate that TRIM $5 \alpha_{\mathrm{hu}}$ is the restriction factor blocking infection of primary CD4 ${ }^{+} \mathrm{T}$ cells by HIV-1-P90A viruses. Furthermore, these experiments suggest that CypA protects the HIV-1 core from TRIM $5 \alpha_{\text {hu }}$ restriction.

\section{CypA-Capsid Interactions Are Required for Efficient HIV-1 Reverse Transcription in Human CD4 ${ }^{+} \mathrm{T}$ Cells} Our analysis shows that HIV-1 strains bearing capsid mutations that disrupt CypA-capsid interactions are unable to infect human $\mathrm{CD}^{+} \mathrm{T}$ cells. To identify the step in the HIV-1 life cycle at which infection is disrupted, we challenged human $\mathrm{CD} 4^{+} \mathrm{T}$ cells with p24-normalized levels of wild-type and mutant HIV-1-GFP viruses and measured reverse transcription, nuclear import, and integration using real-time quantitative polymerase chain reaction (qPCR) (Figure S6). Infection was measured by determining the percentage of GFP-positive cells at $72 \mathrm{~h}$ post-infection (Figure S6A). Consistent with our previous results, HIV-1-P90AGFP and HIV-1-G89V-GFP strains showed weak infection of $\mathrm{CD}^{+} \mathrm{T}$ cells (Figure S6A). Reverse transcription was measured by determining the levels of early reverse transcripts (ERTs) and late reverse transcripts (LRTs) at $12 \mathrm{~h}$ post-infection (Figure S6B). Interestingly, reverse transcription was reduced for HIV-1-P90A-GFP and HIV-1-G89V-GFP, suggesting that measured the levels of 2-long terminal repeat (2-LTR) circles at $36 \mathrm{~h}$ post-infection (Figure $\mathrm{S} 6 \mathrm{C}$ ). Consistent with a reverse transcription block, our results show that both viruses were blocked for nuclear import. Viral integration was determined using Alu$\mathrm{PCR}$ at $66 \mathrm{~h}$ post-infection (Figure S6D). As a control, the integration inhibitor Raltegravir (Ral) was also used. As expected, the integration of HIV-1-P90A and HIV-1-G89V was blocked. Overall, these results suggest that HIV-1 requires interaction with CypA to undergo efficient reverse transcription in human $\mathrm{CD}^{+}$ $T$ cells. These results also suggest that, in the absence of CypA, HIV-1 particles are exposed to TRIM5 $\alpha_{\text {hu }}$, which inhibits reverse transcription.

\section{DISCUSSION}

A few years after the discovery of HIV-1 capsid interaction with CypA (Luban et al., 1993), it was established that CsA treatment disrupted this interaction, which then affected HIV-1 infectivity. It was soon realized that CsA exerted varying effects on HIV-1 infection, depending upon the human cell lines used. Although CypA-capsid interactions have been studied for over 25 years, the mechanism by which CsA affects HIV-1 infection remains elusive. Here, we explore the role of CypA-capsid interactions in human lymphocytes.

Several recent studies have suggested that TRIM $5 \alpha_{\text {hu }}$ may function as an HIV-1 restriction factor (Jimenez-Guardeño 
A

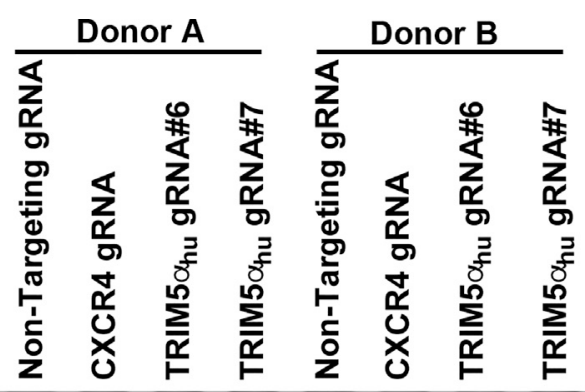

anti-TRIM5 $\alpha_{\mathrm{hu}} \quad 50 \mathrm{kDa}$ -

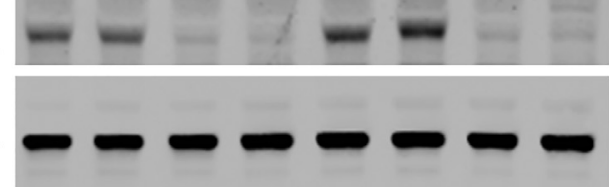

anti-GAPDH $37 \mathrm{kDa}$ -

B

Donor A

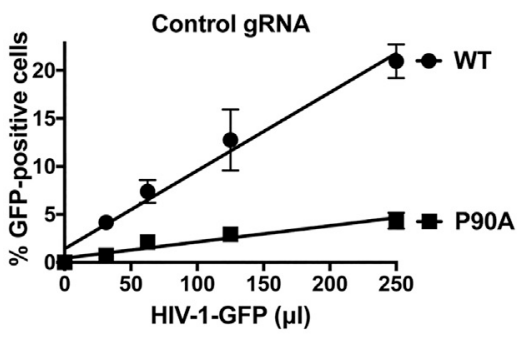

TRIM5 $\alpha_{\text {hu }}$ gRNA\#6
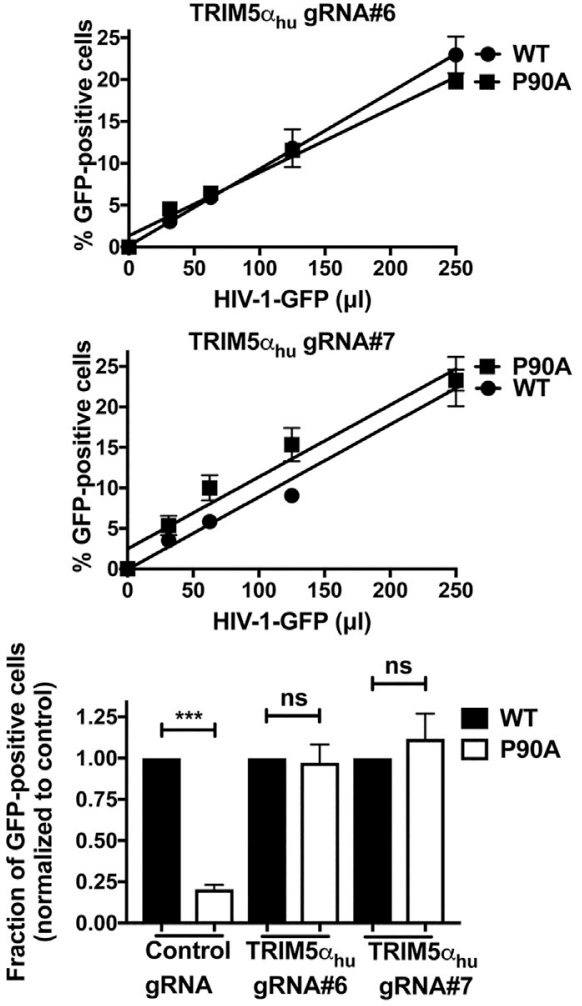

Donor B
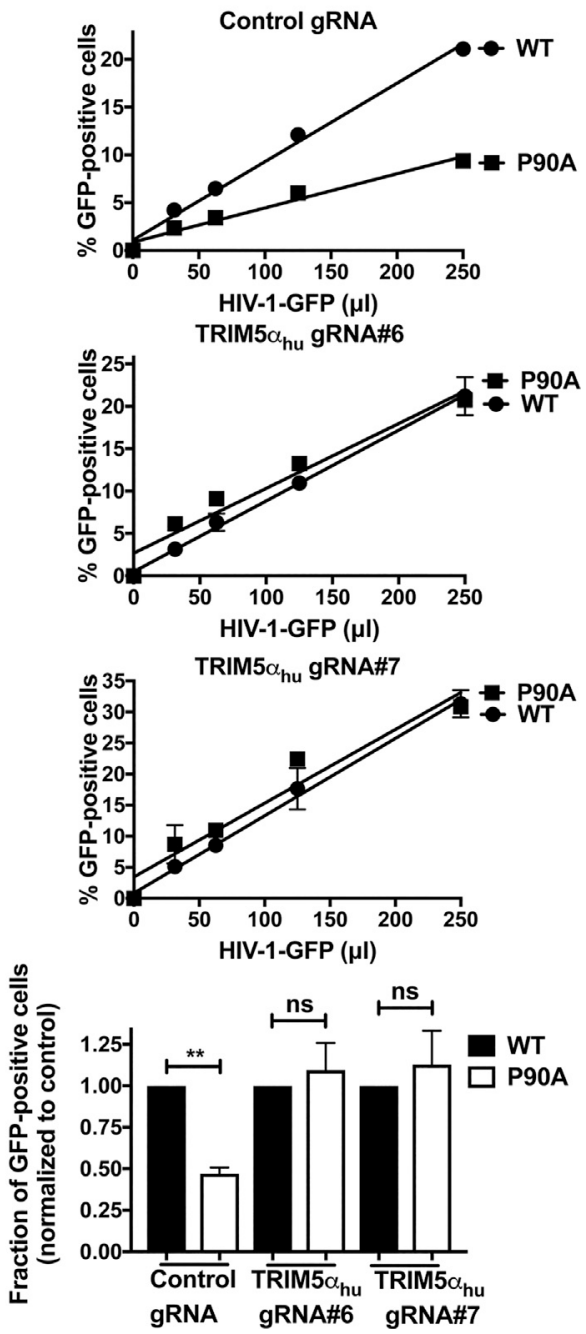
et al., 2019; OhAinle et al., 2018). This led us to hypothesize that TRIM5 $\alpha_{\text {hu }}$ binds to the HIV-1 core, which was proven by our results. We also show that endogenously expressed TRIM $5 \alpha_{\text {hu }}$ binds to the HIV-1 core. Remarkably, we observed that TRIM $5 \alpha_{\text {hu }}$ showed stronger binding to the HIV-1 core than TRIM5 $\alpha_{\mathrm{rh}}$. Because TRIM5 $\alpha_{\mathrm{hu}}$ and CypA both bind to the HIV-1 core, it is possible that these two factors compete for the HIV-1 core during infection-CypA may modulate the binding of TRIM $5 \alpha_{\text {hu }}$ to the HIV-1 core. We show that depletion of TRIM $5 \alpha_{\text {hu }}$ expression in Jurkat and primary CD4 ${ }^{+} \mathrm{T}$ cells rescue the HIV-1 infectivity phenotype caused by the disruption of CypA-capsid interactions. In cellular extracts, we also observed that CsA treatment increased binding of TRIM5 $\alpha_{\text {hu }}$ to the HIV-1 core. These results were consistent with our hypothesis that CypA modulates the binding of TRIM $5 \alpha_{\text {hu }}$ to the HIV-1 core. The results of the binding experiments suggest that CypA sterically hinders the binding of TRIM $5 \alpha_{\text {hu }}$ to the HIV-1 core, which could explain the observed infectivity phenotype when CypA-capsid interactions were disrupted in lymphocytes. Conversely, we also demonstrate that increasing the amounts of CypA prevents the binding of TRIM5 $\alpha_{\text {hu }}$ to the HIV-1 core. Based on these results, we propose that prevention of CypA binding allows TRIM $5 \alpha_{\mathrm{hu}}$ to bind to the HIV-1 core, consequently inhibiting infection. While this manuscript was under revision, Kim et al. (2019) showed similar results using immunofluorescence microscopy.

Our results indicate that the interaction of $\operatorname{TRIM} 5 \alpha_{\mathrm{hu}}$ with the HIV-1 core leads to restriction of infection. However, several previous studies have shown that overexpression of TRIM $5 \alpha_{\text {hu }}$ has little or no effect on HIV-1 infection (Li et al., 2006; Pham et al., 2010; Yap et al., 2005). One possibility is that restriction of HIV-1 infection by TRIM $5 \alpha_{\text {hu }}$ requires specific cellular cofactors expressed only in human lymphocytes. This cofactor may have been absent or present only in insufficient amounts in other human cell lines that were used for TRIM5 $\alpha_{\text {hu }}$ overexpression experiments. The search for these cofactors in the future is warranted. Alternatively, TRIM $5 \alpha_{\mathrm{hu}}$ might be recruited to the HIV-1 core by other TRIM proteins through the formation of higher-order complexes (Diaz-Griffero et al., 2009): TRIM5 $\alpha$ dimers are known to associate with other dimers and form higher-order self-association complexes. For example, TRIM $5 \alpha_{r h}$ forms higher-order complexes with human TRIM34 and TRIM6 (Li et al., 2011). A third possibility is that TRIM5 $\alpha_{\text {hu }}$ might be recruiting other human TRIM orthologs to the HIV-1 core, which are causing restriction. Future studies will explore the existence of other human TRIM orthologs that may form higher-order complexes with TRIM5 $\alpha_{\text {hu }}$
Mutations in the CypA-binding loop of the capsid, such as P90A and G89V, cause an infectivity defect similar to that caused by CsA treatment during wild-type HIV-1 infection of Jurkat and $\mathrm{CD}^{+} \mathrm{T}$ cells; however, infection of HIV-1 viruses bearing the capsid change A92E or G94D results in an infection that is insensitive to CsA treatment in Jurkat cells (Hatziioannou et al., 2005; Sokolskaja et al., 2004). Here, we show that this insensitivity is due to the lack of TRIM5 $\alpha_{\text {hu }}$ binding to HIV-1-A92E or HIV-1G94D mutant cores. Normal viral infectivity correlated with the inability of TRIM5 $\alpha_{\mathrm{hu}}$ to bind to HIV-1-A92E and HIV-1-G94D cores. Based on these results, it is possible that TRIM $5 \alpha_{h u}$ binds to the CypA-binding loop or in its proximity.

The disruption of CypA-capsid interactions had a stronger effect on viral infectivity in human primary cells compared with cell lines. Mutant HIV-1 (P90A or G89V) infection of PBMCs or CD4 ${ }^{+}$ T cells was 10-20-fold weaker than that of wild-type HIV-1. Similarly, $\mathrm{KD}$ of CypA expression in human primary $\mathrm{CD}^{+} \mathrm{T}$ cells potently blocked HIV-1 infection. In contrast, infection of primary lymphocytes by HIV-1-A92E or HIV-1-G94D was not affected when compared to that of wild-type HIV-1. In addition, depletion of TRIM $5 \alpha_{\mathrm{hu}}$ expression in $\mathrm{CD}^{+}{ }^{+} \mathrm{T}$ cells rescued infectivity of HIV-1-P90A viruses. Taken together, these results show that TRIM $5 \alpha_{\text {hu }}$ blocks HIV-1 infection of human primary lymphocytes when CypA-capsid interactions are disrupted. Consistent with this idea, we observe that the inhibition of infection caused by the disruption of CypA-capsid interactions in $\mathrm{CD}^{+} \mathrm{T}$ cells occurred prior to HIV-1 reverse transcription.

Our work has shown that CypA protects the core from TRIM $5 \alpha_{\text {hu. }}$ Intriguingly, new- and old-world monkeys express a protein in which the TRIM domain of TRIM5 $\alpha$ and CypA form a fusion protein (Brennan et al., 2008; Newman et al., 2008; Sayah et al., 2004). It is possible that evolution may have taken advantage of a positive factor, in this case CypA, and fused to the TRIM domain to develop a restriction factor (i.e., TRIMCyp) in response to CypA protecting the virus against TRIM5 $\alpha$.

Although this work explains the infection phenotype observed when disrupting CypA-capsid interactions during infection, it does not explain the role of CypA in HIV-1 infection. It has been suggested that CypA is involved in nuclear import and integration (Schaller et al., 2011). CypA has also been observed to enter the nucleus with capsid (Burdick et al., 2017). Future experiments will provide mechanistic insights on the works of CypA in HIV-1 infection.

Overall, this work shows the mechanism by which disruption of CypA-capsid interactions affect HIV-1 infection of human primary lymphocytes. Future experiments will explore whether a similar mechanism operates in macrophages or dendritic cells.

Figure 6. Depletion of TRIM5 $\alpha_{\text {hu }}$ Expression in Human CD4 ${ }^{+}$T Cells Rescues Infection of HIV-1-P90A Viruses

(A) Human primary CD4 ${ }^{+} \mathrm{T}$ cells from two different donors were knocked out for TRIM5 $\alpha_{\text {hu }}$ expression using the CRISPR/Cas 9 system, as described in STAR Methods. Briefly, CD4 ${ }^{+}$T cells were electroporated using two different guide RNAs (gRNAs) against TRIM5 $\alpha_{\mathrm{hu}}$ (gRNA\#6 and \#7) together with the Cas9 protein. $72 \mathrm{~h}$ post-electroporation, endogenous expression of TRIM $5 \alpha_{\mathrm{hu}}$ in CD4 ${ }^{+}$T was analyzed by western blotting using antibodies against TRIM $5 \alpha_{\mathrm{hu}}$. For controls, we electroporated a gRNA against CXCR4 and a non-targeting gRNA. Expression of GAPDH was used as a loading control.

(B) Human primary CD4 ${ }^{+}$T cells depleted for TRIM $5 \alpha_{\text {hu }}$ expression were challenged with increasing amounts of HIV-1-GFP or HIV-1-P90A-GFP viruses. Infection was measured at $72 \mathrm{~h}$ post-infection by determining the percentage of GFP-positive cells.

Experiments were performed in duplicates and a representative experiment is shown. The results of two independent experiments normalized to wild-type HIV-1GFP infection with standard deviation are shown. ${ }^{\star *} \mathrm{p}<0.001,{ }^{\star \star *} \mathrm{p}<0.0005$, ns indicates not significant as determined by the unpaired test. 


\section{STAR $\star$ METHODS}

Detailed methods are provided in the online version of this paper and include the following:

- KEY RESOURCES TABLE

- LEAD CONTACT AND MATERIALS AVAILABILITY

- EXPERIMENTAL MODEL AND SUBJECT DETAILS

O Bacterial strains

O Human cell lines

o Human PBMCs

- METHOD DETAILS

O Infection using HIV-1-GFP reporter viruses

O Capsid expression and purification

O Assembly of stabilized HIV-1 capsid tubes

C Capsid binding assay protocol

O Capsid binding assay using in vitro assembled HIV-1

CA-NC complexes

O Preparation of PBMCs and $\mathrm{CD}^{+}{ }^{+} \mathrm{T}$ cells

O Knockdown of TRIM5 $\alpha$ expression in Jurkat cells

○ Generation of TRIM5 $\alpha$ knockout HT1080 cell line

O CRISPR-Cas9 Knock-outs in Primary CD4+ T Cells

O Detection of Reverse Transcripts, 2-LTR circles, and integration in $\mathrm{CD}^{+} \mathrm{T}$ cells

- QUANTIFICATION AND STATISTICAL ANALYSIS

- DATA AND CODE AVAILABILITY

\section{SUPPLEMENTAL INFORMATION}

Supplemental Information can be found online at https://doi.org/10.1016/j celrep.2020.02.100.

\section{ACKNOWLEDGMENTS}

We thank the NIH AIDS repository for important reagents. We are very grateful to Kyusik Kim and Jeremy Luban for reagents and helpful discussions. M.P. and C.B. acknowledge support from National Institutes of Health grant T32 Al07501. F.D.-G. is supported NIH NIAID grant R01 AI087390. J.F.H. is supported by amfAR grant 109504-61-RKRL, with funds raised by generationCURE, the Gilead Sciences Research Scholars Program in HIV, NIH grant K22 Al136691, a supplement from the NIH-supported Third Coast CFAR P30 Al117943, and a supplement from the NIH-sponsored HARC Center P50 GM082250. V.S. and F.D.N. were funded by ANRS (Agence Nationale de Recherche sur le SIDA) grant ECTZ4469.

\section{AUTHOR CONTRIBUTIONS}

F.D.-G. designed the research. A.S., M.P., L.M.S., A.B.R., C.B., A.M.L., V.S., F.D.N., J.H., N.J.K., and J.F.H. performed experiments. J.H. and F.D.-G. analyzed the data. F.D.-G. wrote the manuscript.

\section{DECLARATION OF INTERESTS}

The authors declare no competing interests.

Received: October 11, 2019

Revised: December 23, 2019

Accepted: February 26, 2020

Published: March 17, 2020

\section{REFERENCES}

Berthoux, L., Sebastian, S., Sokolskaja, E., and Luban, J. (2005). Cyclophilin A is required for TRIM5alpha-mediated resistance to HIV-1 in Old World monkey cells. Proc. Natl. Acad. Sci. USA 102, 14849-14853.

Braaten, D., Franke, E.K., and Luban, J. (1996). Cyclophilin A is required for an early step in the life cycle of human immunodeficiency virus type 1 before the initiation of reverse transcription. J. Virol. 70, 3551-3560.

Braaten, D., and Luban, J. (2001). Cyclophilin A regulates HIV-1 infectivity, as demonstrated by gene targeting in human T cells. EMBO J. 20, 13001309.

Brass, A.L., Dykxhoorn, D.M., Benita, Y., Yan, N., Engelman, A., Xavier, R.J., Lieberman, J., and Elledge, S.J. (2008). Identification of host proteins required for HIV infection through a functional genomic screen. Science 319, 921-926.

Brennan, G., Kozyrev, Y., and Hu, S.L. (2008). TRIMCyp expression in Old World primates Macaca nemestrina and Macaca fascicularis. Proc. Natl. Acad. Sci. USA 105, 3569-3574.

Buffone, C., Martinez-Lopez, A., Fricke, T., Opp, S., Severgnini, M., Cifola, I., Petiti, L., Frabetti, S., Skorupka, K., Zadrozny, K.K., et al. (2018). Nup153 Unlocks the Nuclear Pore Complex for HIV-1 Nuclear Translocation in Nondividing Cells. J. Virol. 92, 92.

Burdick, R.C., Delviks-Frankenberry, K.A., Chen, J., Janaka, S.K., Sastri, J., Hu, W.S., and Pathak, V.K. (2017). Dynamics and regulation of nuclear import and nuclear movements of HIV-1 complexes. PLoS Pathog. 13 e1006570.

Burse, M., Shi, J., and Aiken, C. (2017). Cyclophilin A potentiates TRIM5 $\alpha$ inhibition of HIV-1 nuclear import without promoting TRIM5 $\alpha$ binding to the viral capsid. PLoS ONE 12, e0182298.

Butler, S.L., Hansen, M.S., and Bushman, F.D. (2001). A quantitative assay for HIV DNA integration in vivo. Nat. Med. 7, 631-634.

Christ, F., Thys, W., De Rijck, J., Gijsbers, R., Albanese, A., Arosio, D., Emiliani, S., Rain, J.C., Benarous, R., Cereseto, A., and Debyser, Z. (2008). TransportinSR2 imports HIV into the nucleus. Curr. Biol. 18, 1192-1202.

Di Nunzio, F., Danckaert, A., Fricke, T., Perez, P., Fernandez, J., Perret, E., Roux, P., Shorte, S., Charneau, P., Diaz-Griffero, F., and Arhel, N.J. (2012). Human nucleoporins promote HIV-1 docking at the nuclear pore, nuclear import and integration. PLoS ONE 7, e46037.

Di Nunzio, F., Fricke, T., Miccio, A., Valle-Casuso, J.C., Perez, P., Souque, P., Rizzi, E., Severgnini, M., Mavilio, F., Charneau, P., and Diaz-Griffero, F. (2013). Nup153 and Nup98 bind the HIV-1 core and contribute to the early steps of HIV-1 replication. Virology 440, 8-18.

Diaz-Griffero, F., Perron, M., McGee-Estrada, K., Hanna, R., Maillard, P.V., Trono, D., and Sodroski, J. (2008). A human TRIM5alpha B30.2/SPRY domain mutant gains the ability to restrict and prematurely uncoat B-tropic murine leukemia virus. Virology 378, 233-242.

Diaz-Griffero, F., Qin, X.R., Hayashi, F., Kigawa, T., Finzi, A., Sarnak, Z. Lienlaf, M., Yokoyama, S., and Sodroski, J. (2009). A B-box 2 surface patch important for TRIM5alpha self-association, capsid binding avidity, and retrovirus restriction. J. Virol. 83, 10737-10751.

Diaz-Griffero, F., Vandegraaff, N., Li, Y., McGee-Estrada, K., Stremlau, M., Welikala, S., Si, Z., Engelman, A., and Sodroski, J. (2006). Requirements for capsid-binding and an effector function in TRIMCyp-mediated restriction of HIV-1. Virology 351, 404-419.

Fernandez, J., Machado, A.K., Lyonnais, S., Chamontin, C., Gärtner, K., Léger, T., Henriquet, C., Garcia, C., Portilho, D.M., Pugnière, M., et al. (2019). Transportin-1 binds to the HIV-1 capsid via a nuclear localization signal and triggers uncoating. Nat. Microbiol. 4, 1840-1850.

Gamble, T.R., Vajdos, F.F., Yoo, S., Worthylake, D.K., Houseweart, M., Sundquist, W.I., and Hill, C.P. (1996). Crystal structure of human cyclophilin A bound to the amino-terminal domain of HIV-1 capsid. Cell 87, 1285-1294. 
Ganser-Pornillos, B.K., Chandrasekaran, V., Pornillos, O., Sodroski, J.G., Sundquist, W.I., and Yeager, M. (2011). Hexagonal assembly of a restricting TRIM5alpha protein. Proc. Natl. Acad. Sci. USA 108, 534-539.

Hatziioannou, T., Perez-Caballero, D., Cowan, S., and Bieniasz, P.D. (2005). Cyclophilin interactions with incoming human immunodeficiency virus type 1 capsids with opposing effects on infectivity in human cells. J. Virol. 79, 176-183.

Hultquist, J.F., Hiatt, J., Schumann, K., McGregor, M.J., Roth, T.L., Haas, P., Doudna, J.A., Marson, A., and Krogan, N.J. (2019). CRISPR-Cas9 genome engineering of primary CD4(+) T cells for the interrogation of HIV-host factor interactions. Nat. Protoc. 14, 1-27.

Hultquist, J.F., Schumann, K., Woo, J.M., Manganaro, L., McGregor, M.J., Doudna, J., Simon, V., Krogan, N.J., and Marson, A. (2016). A Cas9 Ribonucleoprotein Platform for Functional Genetic Studies of HIV-Host Interactions in Primary Human T Cells. Cell Rep. 17, 1438-1452.

Idica, A., Sevrioukov, E.A., Zisoulis, D.G., Hamdorf, M., Daugaard, I., Kadandale, P., and Pedersen, I.M. (2017). MicroRNA miR-128 represses LINE-1 (L1) retrotransposition by down-regulating the nuclear import factor TNPO1. J. Biol. Chem. 292, 20494-20508.

Jimenez-Guardeño, J.M., Apolonia, L., Betancor, G., and Malim, M.H. (2019). Immunoproteasome activation enables human TRIM5 $\alpha$ restriction of HIV-1. Nat. Microbiol. 4, 933-940.

Keckesova, Z., Ylinen, L.M., and Towers, G.J. (2006). Cyclophilin A renders human immunodeficiency virus type 1 sensitive to Old World monkey but not human TRIM5 alpha antiviral activity. J. Virol. 80, 4683-4690.

Kim, K., Dauphin, A., Komurlu, S., McCauley, S.M., Yurkovetskiy, L., Carbone, C., Diehl, W.E., Strambio-De-Castillia, C., Campbell, E.M., and Luban, J. (2019). Cyclophilin A protects HIV-1 from restriction by human TRIM5 $\alpha$. Nat. Microbiol. 4, 2044-2051.

König, R., Zhou, Y., Elleder, D., Diamond, T.L., Bonamy, G.M., Irelan, J.T., Chiang, C.Y., Tu, B.P., De Jesus, P.D., Lilley, C.E., et al. (2008). Global analysis of host-pathogen interactions that regulate early-stage HIV-1 replication. Cell 135, 49-60.

Krishnan, L., Matreyek, K.A., Oztop, I., Lee, K., Tipper, C.H., Li, X., Dar, M.J., Kewalramani, V.N., and Engelman, A. (2010). The requirement for cellular transportin 3 (TNPO3 or TRN-SR2) during infection maps to human immunodeficiency virus type 1 capsid and not integrase. J. Virol. 84, 397-406.

Lee, K., Ambrose, Z., Martin, T.D., Oztop, I., Mulky, A., Julias, J.G., Vandegraaff, N., Baumann, J.G., Wang, R., Yuen, W., et al. (2010). Flexible use of nuclear import pathways by HIV-1. Cell Host Microbe 7, 221-233.

Levin, A., Hayouka, Z., Friedler, A., and Loyter, A. (2010). Transportin 3 and importin $\alpha$ are required for effective nuclear import of HIV-1 integrase in virus-infected cells. Nucleus 1, 422-431.

Li, Y., Kar, A.K., and Sodroski, J. (2009). Target cell type-dependent modulation of human immunodeficiency virus type 1 capsid disassembly by cyclophilin A. J. Virol. 83, 10951-10962.

Li, Y., Li, X., Stremlau, M., Lee, M., and Sodroski, J. (2006). Removal of arginine 332 allows human TRIM5alpha to bind human immunodeficiency virus capsids and to restrict infection. J. Virol. 80, 6738-6744.

Li, X., Yeung, D.F., Fiegen, A.M., and Sodroski, J. (2011). Determinants of the higher order association of the restriction factor TRIM5alpha and other tripartite motif (TRIM) proteins. J. Biol. Chem. 286, 27959-27970.

Lienlaf, M., Hayashi, F., Di Nunzio, F., Tochio, N., Kigawa, T., Yokoyama, S., and Diaz-Griffero, F. (2011). Contribution of E3-ubiquitin ligase activity to HIV-1 restriction by TRIM5alpha(rh): structure of the RING domain of TRIM5alpha. J. Virol. 85, 8725-8737.

Lin, T.Y., and Emerman, M. (2008). Determinants of cyclophilin A-dependent TRIM5 alpha restriction against HIV-1. Virology 379, 335-341.

Luban, J., Bossolt, K.L., Franke, E.K., Kalpana, G.V., and Goff, S.P. (1993). Human immunodeficiency virus type 1 Gag protein binds to cyclophilins A and B. Cell 73, 1067-1078.
Matreyek, K.A., and Engelman, A. (2011). The requirement for nucleoporin NUP153 during human immunodeficiency virus type 1 infection is determined by the viral capsid. J. Virol. 85, 7818-7827.

Matreyek, K.A., Yücel, S.S., Li, X., and Engelman, A. (2013). Nucleoporin NUP153 phenylalanine-glycine motifs engage a common binding pocket within the HIV-1 capsid protein to mediate lentiviral infectivity. PLoS Pathog. 9, e1003693.

Mbisa, J.L., Delviks-Frankenberry, K.A., Thomas, J.A., Gorelick, R.J., and Pathak, V.K. (2009). Real-time PCR analysis of HIV-1 replication post-entry events. Methods Mol. Biol. 485, 55-72.

Meehan, A.M., Saenz, D.T., Guevera, R., Morrison, J.H., Peretz, M., Fadel, H.J., Hamada, M., van Deursen, J., and Poeschla, E.M. (2014). A cyclophilin homology domain-independent role for Nup358 in HIV-1 infection. PLoS Pathog. 10, e1003969.

Newman, R.M., Hall, L., Kirmaier, A., Pozzi, L.A., Pery, E., Farzan, M., O’Neil, S.P., and Johnson, W. (2008). Evolution of a TRIM5-CypA splice isoform in old world monkeys. PLoS Pathog. 4, e1000003.

Ocwieja, K.E., Brady, T.L., Ronen, K., Huegel, A., Roth, S.L., Schaller, T., James, L.C., Towers, G.J., Young, J.A., Chanda, S.K., et al. (2011). HIV integration targeting: a pathway involving Transportin-3 and the nuclear pore protein RanBP2. PLoS Pathog. 7, e1001313.

OhAinle, M., Helms, L., Vermeire, J., Roesch, F., Humes, D., Basom, R., Delrow, J.J., Overbaugh, J., and Emerman, M. (2018). A virus-packageable CRISPR screen identifies host factors mediating interferon inhibition of HIV. eLife 7, 7.

Perron, M.J., Stremlau, M., Lee, M., Javanbakht, H., Song, B., and Sodroski, J. (2007). The human TRIM5alpha restriction factor mediates accelerated uncoating of the N-tropic murine leukemia virus capsid. J. Virol. 81, 21382148.

Pham, Q.T., Bouchard, A., Grütter, M.G., and Berthoux, L. (2010). Generation of human TRIM5alpha mutants with high HIV-1 restriction activity. Gene Ther $17,859-871$.

Pornillos, O., Ganser-Pornillos, B.K., Kelly, B.N., Hua, Y., Whitby, F.G., Stout, C.D., Sundquist, W.I., Hill, C.P., and Yeager, M. (2009). X-ray structures of the hexameric building block of the HIV capsid. Cell 137, 1282-1292.

Ptak, R.G., Gallay, P.A., Jochmans, D., Halestrap, A.P., Ruegg, U.T., Pallansch, L.A., Bobardt, M.D., de Béthune, M.P., Neyts, J., De Clercq, E., et al (2008). Inhibition of human immunodeficiency virus type 1 replication in human cells by Debio-025, a novel cyclophilin binding agent. Antimicrob. Agents Chemother. 52, 1302-1317.

Sayah, D.M., Sokolskaja, E., Berthoux, L., and Luban, J. (2004). Cyclophilin A retrotransposition into TRIM5 explains owl monkey resistance to HIV-1. Nature $430,569-573$.

Schaller, T., Ocwieja, K.E., Rasaiyaah, J., Price, A.J., Brady, T.L., Roth, S.L., Hué, S., Fletcher, A.J., Lee, K., KewalRamani, V.N., et al. (2011). HIV-1 capsid-cyclophilin interactions determine nuclear import pathway, integration targeting and replication efficiency. PLoS Pathog. 7, e1002439.

Selyutina, A., Bulnes-Ramos, A., and Diaz-Griffero, F. (2018). Binding of host factors to stabilized HIV-1 capsid tubes. Virology 523, 1-5.

Sherry, B., Zybarth, G., Alfano, M., Dubrovsky, L., Mitchell, R., Rich, D., Ulrich, P., Bucala, R., Cerami, A., and Bukrinsky, M. (1998). Role of cyclophilin A in the uptake of HIV-1 by macrophages and T lymphocytes. Proc. Natl. Acad. Sci. USA 95, 1758-1763.

Sokolskaja, E., Sayah, D.M., and Luban, J. (2004). Target cell cyclophilin A modulates human immunodeficiency virus type 1 infectivity. J. Virol. 78, 12800-12808.

Stremlau, M., Perron, M., Lee, M., Li, Y., Song, B., Javanbakht, H., Diaz-Griffero, F., Anderson, D.J., Sundquist, W.I., and Sodroski, J. (2006a). Specific recognition and accelerated uncoating of retroviral capsids by the TRIM5alpha restriction factor. Proc. Natl. Acad. Sci. USA 103, 5514-5519.

Stremlau, M., Song, B., Javanbakht, H., Perron, M., and Sodroski, J. (2006b). Cyclophilin A: an auxiliary but not necessary cofactor for TRIM5alpha restriction of HIV-1. Virology 351, 112-120. 
Sundquist, W.I., and Hill, C.P. (2007). How to assemble a capsid. Cell 131, 17-19.

Thali, M., Bukovsky, A., Kondo, E., Rosenwirth, B., Walsh, C.T., Sodroski, J., and Göttlinger, H.G. (1994). Functional association of cyclophilin A with HIV1 virions. Nature 372, 363-365.

Thys, W., De Houwer, S., Demeulemeester, J., Taltynov, O., Vancraenenbroeck, R., Gérard, M., De Rijck, J., Gijsbers, R., Christ, F., and Debyser, Z. (2011). Interplay between HIV entry and transportin-SR2 dependency. Retrovirology 8,7 .

Towers, G.J., Hatziioannou, T., Cowan, S., Goff, S.P., Luban, J., and Bieniasz, P.D. (2003). Cyclophilin A modulates the sensitivity of HIV-1 to host restriction factors. Nat. Med. 9, 1138-1143.

Valle-Casuso, J.C., Di Nunzio, F., Yang, Y., Reszka, N., Lienlaf, M., Arhel, N., Perez, P., Brass, A.L., and Diaz-Griffero, F. (2012). TNPO3 is Required for
HIV-1 Replication After Nuclear Import but Prior to Integration and Binds the HIV-1 Core. J Virol. 86, 5931-5936.

Wainberg, M.A., Dascal, A., Blain, N., Fitz-Gibbon, L., Boulerice, F., Numazaki, K. and Tremblay, M. (1988). The effect of cyclosporine A on infection of susceptible cells by human immunodeficiency virus type 1. Blood 72, 1904-1910.

Yap, M.W., Nisole, S., and Stoye, J.P. (2005). A single amino acid change in the SPRY domain of human Trim5alpha leads to HIV-1 restriction. Curr. Biol. 15 73-78.

Yin, L., Braaten, D., and Luban, J. (1998). Human immunodeficiency virus type 1 replication is modulated by host cyclophilin A expression levels. J. Virol. 72, 6430-6436.

Zhou, H., Xu, M., Huang, Q., Gates, A.T., Zhang, X.D., Castle, J.C., Stec, E., Ferrer, M., Strulovici, B., Hazuda, D.J., and Espeseth, A.S. (2008). Genomescale RNAi screen for host factors required for HIV replication. Cell Host Microbe 4, 495-504. 


\section{STAR $\star M E T H O D S$}

\section{KEY RESOURCES TABLE}

\begin{tabular}{|c|c|c|}
\hline REAGENT or RESOURCE & SOURCE & IDENTIFIER \\
\hline \multicolumn{3}{|l|}{ Antibodies } \\
\hline Mouse monoclonal anti-FLAG M2 & Sigma-Aldrich & Cat\# F1804; RRID:AB_262044 \\
\hline Mouse monoclonal anti-hemagglutinin (HA) & Sigma-Aldrich & Cat\# H3663; RRID:AB_262051 \\
\hline Mouse monoclonal anti-Cyclophilin A (human) & Abcam & Cat\# ab58144; RRID:AB_941220 \\
\hline Rabbit monoclonal anti-TRIM5 $\alpha$ (human, monkey) & Cell Signaling Technology & Cat\# 14326S; RRID:AB_2798451 \\
\hline $\begin{array}{l}\text { Mouse monoclonal anti-glyceraldehyde-3-phosphate } \\
\text { dehydrogenase (GAPDH) }\end{array}$ & Invitrogen (Thermo Fisher Scientific) & Cat\# AM4300; RRID:AB_437392 \\
\hline Mouse monoclonal anti-HIV-1 p24 (183-H12-5C) & NIH AIDS Reagent Program & Cat\# 3637; RRID:CVCL_9N48 \\
\hline Goat anti-Mouse IRDye 680LT & LI-COR & Cat\# 925-68020; RRID:AB_2687826 \\
\hline Goat anti-Rabbit IRDye 680LT & LI-COR & Cat\# 926-68021; RRID:AB_10706309 \\
\hline Goat anti-Mouse IRDye $800 \mathrm{CW}$ & LI-COR & Cat\# 926-32210; RRID:AB_621842 \\
\hline Goat anti-Rabbit IRDye $800 \mathrm{CW}$ & LI-COR & Cat\# 925-32211; RRID:AB_2651127 \\
\hline $\begin{array}{l}\text { Rabbit monoclonal anti-glyceraldehyde-3-phosphate } \\
\text { dehydrogenase (GAPDH) }\end{array}$ & Cell Signaling Technology & Cat \#2118S; RRID:AB_437392 \\
\hline \multicolumn{3}{|l|}{ Bacterial and Virus Strains } \\
\hline E. Coli one-shoot BL21star (DE3) & Invitrogen & Cat\#C601003 \\
\hline E. Coli $\mathrm{DH} 5 \alpha$ competent cells & Zymo Research & Cat\# T3007 \\
\hline N-MLV & Diaz-Griffero et al., 2008 & N/A \\
\hline B-MLV & Diaz-Griffero et al., 2008 & N/A \\
\hline HIV-1 NL4-3 & This paper & N/A \\
\hline HIV-1-G89V & This paper & N/A \\
\hline HIV-1-P90A & This paper & N/A \\
\hline HIV-1-A92E & This paper & N/A \\
\hline HIV-1-G94D & This paper & N/A \\
\hline HIV-1 NL4-3 Nef:IRES:GFP & Hultquist et al., 2016 & N/A \\
\hline \multicolumn{3}{|l|}{ Biological Samples } \\
\hline Healthy adult Peripheral Blood Mononuclear Cells (PBMCs) & LifeSource/Vitalant & N/A \\
\hline \multicolumn{3}{|l|}{ Chemicals, Peptides, and Recombinant Proteins } \\
\hline Cyclosporin A & Millipore Sigma & Cat\#: PHR1092; CAS: 59865-13-3 \\
\hline Dimethyl sulfoxide (DMSO) & Sigma-Aldrich & Cat\#: D2438; CAS: 67-68-5 \\
\hline Difco LB Broth, Miller (Luria-Bertani) & Fisher Scientific & Cat\#: BD244610 \\
\hline Isopropyl $\beta$-D-1-thiogalactopyranoside & Sigma-Aldrich & Cat\#: I5502; CAS: 367-93-1 \\
\hline cOmplete EDTA-free protease inhibitor cocktail & Millipore Sigma & Cat\#: 11873580001 \\
\hline Tris (TRIS(HYDROXYMETHYL)AMINOMETHANE) & Crystalgen & Cat\#300-844-5000; CAS: 77-86-1 \\
\hline Sodium Chloride $(\mathrm{NaCl})$ & Crystalgen & Cat\# 300-747-5000; CAS: 767-14-5 \\
\hline$\beta$-Mercaptoethanol (BME) & Acros organics & Cat\# 125470010; CAS: 60-24-2 \\
\hline 2-(N-morpholino) ethanesulfonic acid (MES) & Calbiochem & Cat\# 475893; CAS: 4432-31-9 \\
\hline Magnesium Chloride $\left(\mathrm{MgCl}_{2}\right)$ & Sigma-Aldrich & Cat\# M2670; CAS: 7791-18-6 \\
\hline Potassium Chloride (KCl) & Fisher Scientific & Cat\# BP366-1; CAS: 7447-40-7 \\
\hline Dithiothreitol (DTT) & VWR & Cat\# 97061-340; CAS: 3483-12-3 \\
\hline D-(+)-Sucrose & VWR & Cat\# 97061-432; CAS: 57-50-1 \\
\hline Human IL-2 & Cell Signaling Technology & Cat\# 8907SF \\
\hline Phytohemagglutinin-L (PHA-L) & Millipore Sigma & Cat\# 11249738001 \\
\hline Human IL-2 & MACS Miltenyi Biotec & Cat\# 130-097-742 \\
\hline
\end{tabular}

(Continued on next page) 


\begin{tabular}{|c|c|c|}
\hline \multicolumn{3}{|l|}{ Continued } \\
\hline REAGENT or RESOURCE & SOURCE & IDENTIFIER \\
\hline Anti-Human CD3 (UCHT1) & Tonbo Biosciences & Cat\# 70-0038-U100; RRID:AB_2621475 \\
\hline Anti-Human CD28 (CD28.2) & Tonbo Biosciences & Cat\# 70-0289-U100; RRID:AB_2621493 \\
\hline Cas9-NLS Recombinant Protein, purified, 40uM & MacroLab Berkeley & N/A \\
\hline Dulbecco's Phosphate-Buffered Salt (PBS) Solution 1X & Corning & $21031 \mathrm{CV}$ \\
\hline EDTA, pH 8.0, 0.5M & Corning & $46034 \mathrm{Cl}$ \\
\hline \multicolumn{3}{|l|}{ Critical Commercial Assays } \\
\hline QuikChange II site-directed mutagenesis kit & Agilent & Cat\#: 200523 \\
\hline CD4+ T Cell Isolation Kit, human & MACS Miltenyi Biotec & Cat\# 130-096-533 \\
\hline EasySep Human CD4+ T Cell Isolation Kit & STEMCELL & Cat\# 17952 \\
\hline P3 Primary Cell 96-well Nucleofector Kit & Lonza & Cat\# V4SP-3096 \\
\hline T Cell Activation/Expansion Kit, human & MACS Miltenyi Biotec & Cat\# 130-091-441 \\
\hline QIAamp DNA Micro Kit & QIAGEN & Cat\# 56304 \\
\hline \multicolumn{3}{|l|}{ Experimental Models: Cell Lines } \\
\hline Human: Jurkat E6.1 & ATCC & TIB-152 \\
\hline Human: 293T/17 & ATCC & CRL-11268 \\
\hline Human: HT1080 & ATCC & CCL-121 \\
\hline \multicolumn{3}{|l|}{ Oligonucleotides } \\
\hline $\begin{array}{l}\text { All standard cloning primers for site- } \\
\text { directed mutagenesis }\end{array}$ & Integrated DNA Technologies & $\mathrm{N} / \mathrm{A}$ \\
\hline $\begin{array}{l}\text { Early reverse transcripts (ERT) hRU5-F, } \\
5^{\prime} \text {-GCCTCAATAAAGCTTGCCTTGA-3' }\end{array}$ & Mbisa et al., 2009 & $\mathrm{~N} / \mathrm{A}$ \\
\hline $\begin{array}{l}\text { Early reverse transcripts (ERT) hRU5-R, } \\
\text { 5'-TGACTAAAAGGGTCTGAGGGATCT-3' }\end{array}$ & Mbisa et al., 2009 & $\mathrm{~N} / \mathrm{A}$ \\
\hline $\begin{array}{l}\text { ERT probe, } 5^{\prime} \text {-(FAM)-AGAGTCACACAAC } \\
\text { AGACGGGCACACACTA-(TAMRA)- } 3^{\prime}\end{array}$ & Mbisa et al., 2009 & $\mathrm{~N} / \mathrm{A}$ \\
\hline $\begin{array}{l}\text { Late Reverse Transcripts (LTR) MH531, } \\
\text { 5'-TGTGTGCCCGTCTGTTGTGT-3', }\end{array}$ & Butler et al., 2001 & $\mathrm{~N} / \mathrm{A}$ \\
\hline $\begin{array}{l}\text { Late Reverse Transcripts (LTR) MH532, } \\
\text { 5'-GAGTCCTGCGTCGAGAGAGC-3' }\end{array}$ & Butler et al., 2001 & $\mathrm{~N} / \mathrm{A}$ \\
\hline $\begin{array}{l}\text { LRT-Probe, } 5^{\prime} \text {-(FAM)-CAGTGGCGCCCG } \\
\text { AACAGGGA-(TAMRA)--3' }\end{array}$ & Butler et al., 2001 & $\mathrm{~N} / \mathrm{A}$ \\
\hline $\begin{array}{l}\text { 2-LTR circles MH535, 5' -AACTAGGGAA } \\
\text { CCCACTGCTTAAG-3' }\end{array}$ & Butler et al., 2001 & $\mathrm{~N} / \mathrm{A}$ \\
\hline $\begin{array}{l}\text { 2-LTR circles MH536, 5'-TCCACAGATC } \\
\text { AAGGATATCTTGTC-3' }\end{array}$ & Butler et al., 2001 & $\mathrm{~N} / \mathrm{A}$ \\
\hline $\begin{array}{l}\text { 2-LTR probe MH603, 5'-(FAM)-ACACTAC } \\
\text { TTGAAGCACTCAAG-GCAAGCTIT-(TAMRA)-3' }\end{array}$ & Butler et al., 2001 & $\mathrm{~N} / \mathrm{A}$ \\
\hline Table S1 Primers and RNA guides & $\mathrm{N} / \mathrm{A}$ & $\mathrm{N} / \mathrm{A}$ \\
\hline \multicolumn{3}{|l|}{ Recombinant DNA } \\
\hline pET-11a & EMD Mollipore & Cat \# 69436 \\
\hline Plasmid: CA A14C/E45C in pET-11a & Selyutina et al., 2018 & N/A \\
\hline Plasmid: CA A14C/E45C/P90A in pET-11a & Selyutina et al., 2018 & N/A \\
\hline Plasmid: CA A14C/E45C/A92E in pET-11a & This paper & N/A \\
\hline Plasmid: CA A14C/E45C/G94D in pET-11a & This paper & N/A \\
\hline pLKO1 & Sigma & Cat\# 10878 \\
\hline pLKO1-shRNA-TRIM5 $\alpha_{\text {hu }}$ & Sigma & Cat\# 13478 \\
\hline Plasmid: human TRIM5 $\alpha-\mathrm{HA}$ in pLPCX & Perron et al., 2007 & N/A \\
\hline Plasmid: rhesus TRIM $5 \alpha-\mathrm{HA}$ in pLPCX & Stremlau et al., $2006 a$ & N/A \\
\hline Plasmid: Tat & Stremlau et al., $2006 a$ & $\mathrm{~N} / \mathrm{A}$ \\
\hline
\end{tabular}




\begin{tabular}{|c|c|c|}
\hline Continued & & \\
\hline REAGENT or RESOURCE & SOURCE & IDENTIFIER \\
\hline Plasmid: Rev & Stremlau et al., 2006a & N/A \\
\hline Plasmid: VSVg & Stremlau et al., 2006 & N/A \\
\hline Other & & \\
\hline HiTrap Q HP 5mL & GE Healthcare & Cat\# 17115401 \\
\hline HiTrap SP HP 5mL & GE Healthcare & Cat\# 17115201 \\
\hline Centriprep Centrifugal Filter Unit $30 \mathrm{kDa}$ & Millipore Sigma & Cat\# 4306 \\
\hline SnakeSkin Dialysis Tubing, 10K MWCO & Fisher Scientific & Cat\# 68100 \\
\hline GE Healthcare Ficoll-Paque PLUS Media & Fisher Scientific & Cat\# 45001-749 \\
\hline Hanks' Balanced Salt solution & Sigma-Aldrich & Cat\# H6648 \\
\hline LS Columns & MACS Miltenyi Biotec & Cat\# 130-042-401 \\
\hline MS Columns & MACS Miltenyi Biotec & Cat\# 130-042-201 \\
\hline SepMate PBMC Isolation Tubes & STEMCELL & Cat\# 85450 \\
\hline Maxima Probe/ROX qPCR Master Mix (2X) & ThermoScientific & Cat\#K0231 \\
\hline TURBO DNase $(2 \mathrm{U} / \mu \mathrm{L})$ & Invitrogen & Cat\#AM2238 \\
\hline Platinum SuperFi DNA Polymerase & Invitrogen & Cat\#12351050 \\
\hline iTaq Universal SYBR $\circledast$ Green Supermix & Biorad & Cat\#1725124 \\
\hline $0.2 \mathrm{ml}$ PCR 8-tube with attached clear flat caps, natural & USA Scientific & $1402-3900$ \\
\hline Fetal Bovine Serum (FBS, heat-inactivated) & GIBCO & $16140-071$ \\
\hline RPMI-1640 (high glucose) & Corning & MT10-017-CV \\
\hline Penicillin-streptomycin (5 mg/mL) & Corning & MT10-040-CV \\
\hline Sodium pyruvate (100x) & Corning & MT25-000-Cl \\
\hline HEPES (100x) & Fisher / HyClone & SH3023701 \\
\hline DMEM (high glucose) & Corning & MT10-017-CV \\
\hline
\end{tabular}

\section{LEAD CONTACT AND MATERIALS AVAILABILITY}

This study generated the following new plasmids: pET11A-A14C/E45C/A92E, pET11A-A14C/E45C/G94D, HIV-1-P90A, HIV-1G89V, HIV-1-A92E and HIV-1-G94D. Plasmids generated and used in this study are available upon request. Further information and requests for plasmids, resources, and reagents should be directed to and will be fulfilled by the lead contact Felipe Diaz-Griffero (Felipe.Diaz-Griffero@einsteinmed.org)

\section{EXPERIMENTAL MODEL AND SUBJECT DETAILS}

\section{Bacterial strains}

All molecular cloning was carried out in E. coli $\mathrm{DH} 5 \alpha$ competent cells. All recombinant proteins were expressed and purified from E. coli one-shot BL21star (DE3) strain. Both bacterial stains were routinely grown in Luria-Bertani (LB) medium at $37^{\circ} \mathrm{C}($ or at the indicated temperatures) while shaking at 200 RPM.

\section{Human cell lines}

Human Jurkat lymphocytes cells obtained from the American type culture collection (ATCC) were grown at $37^{\circ} \mathrm{C}$ in Roswell Park Memorial Institute (RPMI) medium supplemented with 10\% fetal bovine serum (FBS) and 1\% penicillin-streptomycin. Human $293 \mathrm{~T} / 17$ and HT1080 (ATCC) cells were grown at $37^{\circ} \mathrm{C}$ in Dulbecco's modified eagle medium (DMEM) supplemented with $10 \%$ FBS and $1 \%$ penicillin-streptomycin.

\section{Human PBMCs}

Adult Peripheral Blood Mononuclear Cells (PBMCs) from anonymous, healthy donors were isolated from donated buffy coat products, a post-centrifugation product from a single whole blood donation that contains white blood cells and platelets (Lifesource/Vitalant, Chicago, and New York Blood Center, New York). 


\section{METHOD DETAILS}

\section{Infection using HIV-1-GFP reporter viruses}

Recombinant human immunodeficiency virus-1 (HIV-1) strains such as HIV-1-G89V, HIV-1-P90A, HIV-1-A92E and HIV-1-G94D expressing GFP and pseudotyped with VSV-G were prepared as previously described (Diaz-Griffero et al., 2008). To produce

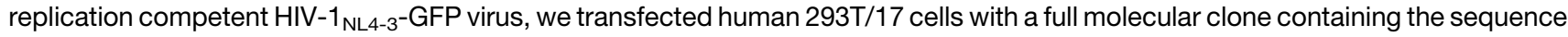

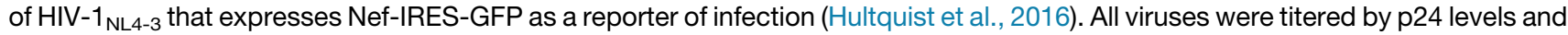
infectivity. Viral challenges were performed in 24-well plates by infecting 50,000 cells (Jurkat, PBMCs, or CD4 ${ }^{+} \mathrm{T}$ cells) per well. Infection was determined by measuring the percentage of GFP-positive cells using flow cytometry (BD FACSCelesta).

\section{Capsid expression and purification}

pET-11a vectors were used to express the HIV-1 capsid protein containing the A14C and E45C mutations. Point mutations P90A, A92E and G94D were introduced using the QuikChange II site-directed mutagenesis kit (Stratagene) according to the manufacturer's instructions. All proteins were expressed in Escherichia coli one-shot BL21star (DE3) cells (Invitrogen), as previously described (Selyutina et al., 2018). Briefly, cells were inoculated in Luria-Bertani (LB) medium and cultured at $30^{\circ} \mathrm{C}$ until mid-log phase $\left(A_{600}\right.$, 0.6-0.8). Protein expression was induced with $1 \mathrm{mM}$ isopropyl- $\beta$ - $d$-thiogalactopyranoside (IPTG) overnight at $18^{\circ} \mathrm{C}$. Cells were harvested by centrifugation at $5,000 \times \mathrm{g}$ for $10 \mathrm{~min}$ at $4{ }^{\circ} \mathrm{C}$, and pellets were stored at $-80^{\circ} \mathrm{C}$ until purification. Purification of capsids was carried out as follows. Pellets from $2 \mathrm{~L}$ cultures were lysed by sonication (Qsonica microtip: 4420; $A=45 ; 2$ min; 2 s on; 2 s off for 12 cycles), in $40 \mathrm{~mL}$ of lysis buffer $(50 \mathrm{mM}$ Tris $\mathrm{pH}=8,50 \mathrm{mM} \mathrm{NaCl}, 100 \mathrm{mM} \beta$-mercaptoethanol, and Complete EDTA-free protease inhibitor tablets). Cell debris was removed by centrifugation at $40,000 \times \mathrm{g}$ for $20 \mathrm{~min}$ at $4{ }^{\circ} \mathrm{C}$. Proteins from the supernatant were precipitated by incubation with one-third the volume of saturated ammonium sulfate containing $100 \mathrm{mM} \beta$-mercaptoethanol for $20 \mathrm{~min}$ at $4^{\circ} \mathrm{C}$, and centrifugation at $8,000 \times \mathrm{g}$ for $20 \mathrm{~min}$ at $4^{\circ} \mathrm{C}$. Precipitated proteins were resuspended in $30 \mathrm{~mL}$ of buffer A (25 mM 2-(N-morpholino) ethanesulfonic acid (MES) pH 6.5 and $100 \mathrm{mM} \beta$-mercaptoethanol) and sonicated 2-3 times (Qsonica microtip: 4420; $A=45 ; 2$ min; 1 s on; 2 s off). The protein sample was dialyzed three times in buffer $A(2 \mathrm{~h}$, overnight, $2 \mathrm{~h}$ ), sonicated, diluted in $500 \mathrm{~mL}$ of buffer $\mathrm{A}$, and was chromatographed sequentially on a $5 \mathrm{~mL}$ HiTrap Q HP column and on a $5 \mathrm{~mL}$ HiTrap SP FF column (GE Healthcare), which were both pre-equilibrated with buffer A. The capsid protein was eluted from the HiTrap SP FF column using a linear gradient of concentrations ranging from 0-2 $\mathrm{M} \mathrm{NaCl}$. The eluted fraction that had highest protein levels was selected based on absorbance at $280 \mathrm{~nm}$. Pooled fractions were dialyzed three times $(2 \mathrm{~h}$, overnight, $2 \mathrm{~h}$ ) in storage buffer ( $25 \mathrm{mM}$ MES, $2 \mathrm{M}$ $\mathrm{NaCl}, 20 \mathrm{mM} \beta$-mercaptoethanol). The sample was reduced to a concentration of $20 \mathrm{mg} / \mathrm{ml}$ using Centriprep Centrifugal Filter Unit and stored at $-80^{\circ} \mathrm{C}$.

\section{Assembly of stabilized HIV-1 capsid tubes}

One milliliter of monomeric capsid (5 mg/ml) was dialyzed in SnakeSkin dialysis tubing $10 \mathrm{~K}$ MWCO (Thermo Scientific) using a buffer that is high in salt and contains a reducing agent (buffer 1: $50 \mathrm{mM}$ Tris, $\mathrm{pH} 8,1 \mathrm{M} \mathrm{NaCl}, 100 \mathrm{mM} \beta$-mercaptoethanol) at $4{ }^{\circ} \mathrm{C}$ for $8 \mathrm{~h}$. Subsequently the protein was dialyzed using buffer 1 without the reducing agent $\beta$-mercaptoethanol (buffer 2: $50 \mathrm{mM}$ Tris, $\mathrm{pH} 8,1 \mathrm{M}$ $\mathrm{NaCl}$ ) at $4{ }^{\circ} \mathrm{C}$ for $8 \mathrm{~h}$. The absence of $\beta$-mercaptoethanol in the second dialysis allows the formation of disulfide bonds between Cysteine 14 and 45 inter-capsid monomers in the hexamer. Finally, the protein was dialyzed using buffer $3(20 \mathrm{mM}$ Tris, $\mathrm{pH} 8,0$, $40 \mathrm{mM} \mathrm{NaCl}$ ) at $4^{\circ} \mathrm{C}$ for $8 \mathrm{~h}$. Assembled complexes were kept at $4^{\circ} \mathrm{C}$ for up to $1 \mathrm{month}$.

\section{Capsid binding assay protocol}

Human HEK293T cells were transfected for $24 \mathrm{~h}$ with a plasmid expressing the protein of interest $\left(\right.$ TRIM5 $\alpha_{\mathrm{hu}}$ or TRIM5 $\left.\alpha_{\mathrm{rh}}\right)$. The cell medium was completely removed and cells were scraped off the plate and lysed in $300 \mu \mathrm{L}$ of capsid binding buffer (CBB: $10 \mathrm{mM}$ Tris, $\left.\mathrm{pH} 8,0,1,5 \mathrm{mM} \mathrm{MgCl}_{2}, 10 \mathrm{mM} \mathrm{KCl}\right)$. Cells were rotated at $4^{\circ} \mathrm{C}$ for $15 \mathrm{~min}$ and then centrifuged to remove cellular debris $(21,000 \times \mathrm{g}$, $15 \mathrm{~min}, 4^{\circ} \mathrm{C}$ ). Cell lysates were incubated with stabilized HIV-1 capsid tubes for $1 \mathrm{~h}$ at $25^{\circ} \mathrm{C}$. Subsequently, the stabilized HIV-1 capsid tubes were centrifuged at 21,000 $\times \mathrm{g}$ for $2 \mathrm{~min}$. Pellets were washed 2-3 times by resuspension and centrifugation in CBB or phosphate-buffered saline (PBS). Pellets were resuspended in Laemmli buffer $1 \times$ and analyzed by western blot using anti-p24 and the indicated antibodies.

\section{Capsid binding assay using in vitro assembled HIV-1 CA-NC complexes}

Capsid binding assays were performed as described earlier (Lienlaf et al., 2011). Briefly, HIV-1 CA-NC particles were assembled in vitro by incubating in buffer $\mathrm{A}(50 \mathrm{mM}$ Tris $(\mathrm{pH} 8,0), 0.5 \mathrm{mM} \mathrm{NaCl}, 2 \mathrm{mg} / \mathrm{ml}$ DNA oligo-(TG) 50$)$ at $4^{\circ} \mathrm{C}$ overnight. Human HEK293T cells were transfected for $24 \mathrm{~h}$ with a plasmid expressing the protein of interest (TRIM $5 \alpha_{\mathrm{hu}}$ or TRIM $5 \alpha_{\mathrm{rh}}$,). The cell medium was completely removed and cells were scraped off the plate and lysed in $300 \mu \mathrm{L}$ of capsid binding buffer with DTT (CBB+: $10 \mathrm{mM}$ Tris, $\left.\mathrm{pH} 8,0,1,5 \mathrm{mM} \mathrm{MgCl}_{2}, 10 \mathrm{mM} \mathrm{KCl}, 0,5 \mathrm{mM} \mathrm{DTT}\right)$. Cells were rotated at $4^{\circ} \mathrm{C}$ for 15 min and then centrifuged to remove cellular debris $\left(21,000 \times \mathrm{g}, 15 \mathrm{~min}, 4^{\circ} \mathrm{C}\right)$. Cell lysates were incubated with HIV-1 CA-NC complexes capsid tubes for $1 \mathrm{~h}$ at $25^{\circ} \mathrm{C}$. The mixture was spun through a $70 \%$ sucrose cushion $(70 \%$ sucrose, $1 \times \mathrm{PBS})$ at $100,000 \times \mathrm{g}$ in an SW55 rotor (Beckman), $1 \mathrm{~h}, 4^{\circ} \mathrm{C}$. After centrifugation pellets were resuspended in Laemmli buffer $1 \times$ and analyzed by western blot using anti-p24 and anti-HA antibodies. 
Preparation of PBMCs and CD4 ${ }^{+} \mathrm{T}$ cells

PBMCs from healthy donor whole blood were isolated by density gradient centrifugation using Ficoll-Paque Plus (GE Health Care). $40 \mathrm{~mL}$ of whole blood was centrifuged at $300 \times \mathrm{g}$ for $10 \mathrm{~min}$, and the plasma layer was removed and replaced with Hank's Balanced Salt solution (HBSS; Sigma Aldrich). The whole blood was then diluted to a ratio of 1:2 with HBSS with $20 \mathrm{~mL}$ of the diluted blood layered on top of $20 \mathrm{~mL}$ Ficoll-Paque Plus and centrifuged at $300 \times \mathrm{g}$ for $30 \mathrm{~min}$. The resulting buffy coat layer was collected, washed twice with HBSS, and resuspended in RPMI medium containing 10\% (vol/vol) FBS and 1\% (vol/vol) penicillin-streptomycin, and activated with IL-2 (100 U/ml) (Human IL-2; Cell Signaling Technology, \#8907SF) and phytohemagglutinin (1 $\mu \mathrm{g} / \mathrm{ml}) \mathrm{for} 3 \mathrm{days}$. $\mathrm{CD}^{+} \mathrm{T}$ cells were obtained via negative selection from PBMCs using a human $\mathrm{CD} 4^{+} \mathrm{T}$ cell isolation kit (MACS Miltenyi Biotec, \#130-096-533). Per $1 \times 10^{7}$ total cells, PBMCs were resuspended in $40 \mu \mathrm{l} \mathrm{CD} 4^{+} \mathrm{T}$ cell isolation buffer (PBS, $\mathrm{pH} 7.2,0.5 \%$ bovine serum albumin, and $2 \mathrm{mM}$ EDTA). Ten microliters of $\mathrm{CD}^{+} \mathrm{T}$ cell biotin-antibody cocktail was then added and incubated at $4{ }^{\circ} \mathrm{C}$ for $5 \mathrm{~min}$. Thirty microliters of CD4 ${ }^{+} \mathrm{T}$ cell isolation buffer and $20 \mu \mathrm{l}$ of CD4 ${ }^{+} \mathrm{T}$ cell microbead cocktail were then added and further incubated for $10 \mathrm{~min}$ at $4^{\circ} \mathrm{C}$. Depending on the amount of PBMCs isolated, LS or MS Column attached to a MACS Separator was prewashed with $3 \mathrm{~mL}$ or $6 \mathrm{~mL}$ of ice-cold $\mathrm{CD} 4^{+} \mathrm{T}$ cell isolation buffer, respectively. PBMC suspension was added to the column and the flow-through was collected in a $15 \mathrm{~mL}$ tube. The LS or MS Columns were then washed with $3 \mathrm{~mL}$ or $6 \mathrm{~mL}$ of ice-cold CD4 ${ }^{+} \mathrm{T}$ cell isolation buffer, respectively, and the flow-through was collected. The newly isolated CD4 ${ }^{+} \mathrm{T}$ cells were then centrifuged at $800 \mathrm{x}$ $g$ for $5 \mathrm{~min}$ and resuspended in RPMI medium supplemented with IL-2 (100 U/ml).

\section{Knockdown of TRIM5 $\alpha$ expression in Jurkat cells}

Lentiviral particles were produced in human 293T/17 cells by co-transfection of $1 \mu \mathrm{g}$ TAT, $1 \mu \mathrm{g} \mathrm{REV,} 1.5 \mu \mathrm{g} \mathrm{VSVG,} 1 \mu \mathrm{g}$ HDM (codon optimized gag-pol), and $7.5 \mu \mathrm{g}$ of the lentiviral vector pLKO1 or $7.5 \mu \mathrm{g}$ the pLKO1 vector containing an shRNA that targets TRIM5 $\alpha$ (pLKO1-shRNA-TRIM5 $\alpha$ ). Viruses were harvested at $48 \mathrm{~h}$ post-transfection and used to transduce Jurkat cells for 5 days at a 1:1 virus to complete media ratio. Transduced cells were selected in $0.15 \mu \mathrm{g} / \mathrm{ml}$ of puromycin. Cells that stably contained pLKO1 or pLKO1shRNA-TRIM5 $\alpha$ were maintained in puromycin. Expression of TRIM5 $\alpha$ was evaluated by western blotting and by challenging the cells with N-tropic murine leukemia virus (N-MLV) and B-tropic murine leukemia virus (B-MLV).

\section{Generation of TRIM5 $\alpha$ knockout HT1080 cell line}

Human TRIM5 $\alpha$ knockout (KO) HT1080 cell line was generated by using the clustered regulatory interspaced short palindromic repeat (CRISPR)-Cas9 gene system (Edit-R CRISPR-Cas9 gene engineering with SMARTCas9 nucleases; GE Healthcare). The CRISPR genomic guide RNA sequence for human TRIM5 $\alpha$ was designed to target exon 1 near the start codon. The guide RNA construct, human cytomegalovirus (hCMV)-Cas9, and CMV-GFP were co-transfected into HT-1080 cells. After $48 \mathrm{~h}$ of transfection, GFP-positive cells were single-cell sorted by using the FACSAria system (BD Biosciences, Franklin Lakes, NJ, USA). Clonal HT-1080 colonies were expanded and characterized for the loss of TRIM $5 \alpha$ protein expression by western blot analysis using anti-TRIM5 $\alpha$ antibodies and by challenging the cells with N-tropic murine leukemia virus (N-MLV) and B-tropic murine leukemia virus (B-MLV).

\section{CRISPR-Cas9 Knock-outs in Primary CD4+ T Cells}

Detailed protocols for the production of CRISPR-Cas9 ribonucleoprotein complexes (crRNPs) and primary CD4+ T cell editing have been previously published (Hultquist et al., 2016; Hultquist et al., 2019). Briefly, lyophilized crRNA and tracrRNA (Dharmacon) were suspended at a concentration of $160 \mu \mathrm{M}$ in $10 \mathrm{mM}$ Tris- $\mathrm{HCl}(7.4 \mathrm{pH}), 150 \mathrm{mM} \mathrm{KCl}$. $5 \mu \mathrm{L}$ of $160 \mu \mathrm{M}$ crRNA was mixed with $5 \mu \mathrm{L}$ of $160 \mu \mathrm{M}$ tracrRNA and incubated for $30 \mathrm{~min}$ at $37^{\circ} \mathrm{C}$. The gRNA:tracrRNA complexes were then mixed gently with $10 \mu \mathrm{L}$ of $40 \mu \mathrm{M}$ purified Cas9NLS protein (UC-Berkeley Macrolab) to form CRISPR-Cas9 ribonucleoprotein complexes (crRNPs). Five 3.5 $\mu \mathrm{L}$ aliquots were frozen in $0.2 \mathrm{~mL} \mathrm{PCR}$ tubes (USA Scientific) at $-80^{\circ} \mathrm{C}$ until use. crRNA guide sequences used in this study were a combination of sequences derived from the Dharmacon pre-designed Edit-R library for gene knock-out and custom ordered sequences as indicated.

Peripheral blood mononuclear cells (PBMCs) were isolated by density gradient centrifugation using Ficoll-Paque Plus (GE Health Care, \#17-1440-02). PBMCs were washed with PBS 1x three times to remove platelets and suspended at a final concentration of $5^{\star} 10 \wedge 8$ cells $/ \mathrm{mL}$ in PBS 1x, 0.5\% BSA, 2mM EDTA. Bulk CD4+ T cells were subsequently isolated from PBMCs by magnetic negative selection using an EasySep Human CD4+ T Cell Isolation Kit (STEMCELL, per manufacturer's instructions). Isolated CD4+ T cells were suspended in complete Roswell Park Memorial Institute (RPMI), consisting of RPMI-1640 (Sigma) supplemented with 5mM 4-(2-hydroxyethyl)-1-piperazineethanesulfonic acid (HEPES, Corning), $50 \mu \mathrm{g} / \mathrm{mL}$ penicillin/streptomycin (P/S, Corning), 5mM sodium pyruvate (Corning), and 10\% fetal bovine serum (FBS, GIBCO). Media was supplemented with 20 IU/mL IL-2 (Miltenyi) immediately before use. For activation, bulk CD4+ T cells were immediately plated on anti-CD3 coated plates [coated for 12 hours at $4{ }^{\circ} \mathrm{C}$ with $20 \mu \mathrm{g} / \mathrm{mL}$ anti-CD3 (UCHT1, Tonbo Biosciences)] in the presence of $5 \mu \mathrm{g} / \mathrm{mL}$ soluble anti-CD28 (CD28.2, Tonbo Biosciences). Cells were stimulated for 72 hours at $37^{\circ} \mathrm{C} / 5 \% \mathrm{CO} 2$ prior to electroporation. After stimulation, cell purity and activation was verified by CD4/CD25 immunostaining and flow cytometry as previously described (Hultquist et al., 2016; Hultquist et al., 2019).

After three days of stimulation, cells were suspended and counted. Each electroporation reaction consisted of between $5 \times 10^{\wedge} 5$ and $1 \times 10 \_6 \mathrm{~T}$ cells, $3.5 \mu \mathrm{L}$ RNP, and $20 \mu \mathrm{L}$ electroporation buffer. crRNPs were thawed and allowed to come to room-temperature. Immediately prior to electroporation, cells were centrifuged at 400xg for 5 minutes, supernatant was removed by aspiration, and the pellet was resuspended in $20 \mu \mathrm{L}$ of room-temperature P3 electroporation buffer (Lonza) per reaction. $20 \mu \mathrm{L}$ of cell suspension was then gently mixed with each RNP and aliquoted into a 96-well electroporation cuvette for nucleofection with the 4D 96-well shuttle unit 
(Lonza) using pulse code $\mathrm{EH}-115$. Immediately after electroporation, $100 \mu \mathrm{L}$ of pre-warmed media without IL-2 was added to each well and cells were allowed to rest for 30 minutes in a $37^{\circ} \mathrm{C}$ cell culture incubator. Cells were subsequently moved to 96 -well flatbottomed culture plates pre-filled with $100 \mu \mathrm{L}$ warm complete media with IL-2 at $40 \mathrm{U} / \mathrm{mL}$ (for a final concentration of $20 \mathrm{U} / \mathrm{mL}$ ) and anti-CD3/anti-CD2/anti-CD28 beads (T cell Activation and Stimulation Kit, Miltenyi) at a 1:1 bead:cell ratio. Cells were cultured at $37^{\circ} \mathrm{C} / 5 \% \mathrm{CO}_{2}$ in a dark, humidified cell culture incubator for 4 days to allow for gene knock-out and protein clearance, with additional media added on day 2. To check knock-out efficiency, $50 \mu \mathrm{L}$ of mixed culture was removed to a centrifuge tube. Cells were pelleted, supernatant was removed, and pellets were resuspended in $100 \mu \mathrm{L} 2.5 x$ Laemmli Sample Buffer. Protein lysates were heated to $98^{\circ} \mathrm{C}$ for $20 \mathrm{~min}$ before storage at $-20^{\circ} \mathrm{C}$ until western blotting.

Detection of Reverse Transcripts, 2-LTR circles, and integration in CD4+ ${ }^{+}$cells

Total DNA was extracted from $1 \times 10^{6}$ infected cells. Samples were processed at 12, 36, and 66 h post-infection using QIAmp DNA micro kit (QIAGEN). Viral DNA forms of wild-type and mutant HIV-1 were amplified using real-time PCR (Butler et al., 2001; ValleCasuso et al., 2012). $\beta$-actin amplification was used for normalization. ERT, which refers to the early reverse transcripts (prior the minus strand transfer), and LRT, which refers to the whole synthesis of DNA by HIV-1, were measured at $12 \mathrm{~h}$ post-infection. 2 -LTR circles were measured at $36 \mathrm{~h}$ post-infection to assess nuclear import. Provirus integration in cellular genome was measured at $66 \mathrm{~h}$ post-infection using Alu-PCR. Reactions were performed in 1X FastStart Universal Probe Master Mix (Rox) $2 \times($ Roche) in $20 \mu \mathrm{l}$ volume. The PCR reaction consisted of the following steps: initial annealing $\left(50^{\circ} \mathrm{C} 2 \mathrm{~min}\right)$, denaturation step $\left(95^{\circ} \mathrm{C} 15 \mathrm{~min}\right)$, 40 cycles of amplification $\left(95^{\circ} \mathrm{C} 15 \mathrm{~s}, 58^{\circ} \mathrm{C} 30 \mathrm{~s}, 72^{\circ} \mathrm{C} 30 \mathrm{~s}\right)$. Primer or probe sequences are as follows: ERT hRU5-F2: $5^{\prime}-\mathrm{GCCTCAA}$ TAAAGCTTGCCTTGA-3'; hRU5-R: 5'-TGACTAAAAGGGTCTGAGGGATCT-3'; ERT-Probe: 5'-(FAM)-AGAGTCACACAACAGACG GGCACACACTA-(TAMRA)-3'. LRT MH531: 5'-TGTGTGCCCGTCTGTTGTGT-3'; MH532: 5'-GAGTCCTGCGTCGAGAGAGC-3'; LRT-Probe: 5'-(FAM)-CAGTGGCGCCCGAACAGGGA-(TAMRA)-3'. 2-LTR circles: MH535: 5'-AACTAGGGAACCCACTGCTTAAG-3'; MH536: 5'-TCCACAGATCAAGGATATCTTGTC-3'; 2-LTR probe: MH603: 5'-(FAM)-ACACTACTTGAAGCACTCAAG-GCAAGCTTT(TAMRA)-3'. Alu-PCR $1^{\text {st }}$ round: Alu 1: 5'-TCCCAGCTACTCGGGAGGCTGAGG-3'; Alu 2: 5'-GCCTCCCAAAGTGCTGGGATTACAG3'; Lambda U3: 5'-ATGCCACGTAAGCGAAACTTTCCGCTGGGGACTTTCCAGGG-3'. Alu quantitative PCR $2^{\text {nd }}$ round: Lambda: (5'-ATGCCACGTAAGCGAAACT-3'); U5: (5'-CTGACTAAAAGGGTCTGAGG-3'; Probe: 5'-(FAM)- TTAAGCCTCAATAAAGCTTGCCTT GAGTGC-(TAMRA)-3'. $\beta$-actin: FX: 5'-AACACCCCAGCCATGTACGT-3', RX: 5-CGGTGAGGATCTTCATGAGGTAGT-3', Actin-Probe: (6FAM)-CCAGCCAGGTCCAGACGCAGGA-(BBQ)-3'.

\section{Western blot analysis}

Cells were lysed in lysis buffer (50 mM Tris [pH 8.0], $280 \mathrm{mM} \mathrm{NaCl}, 0.5 \%$ IGEPAL 40, $10 \%$ glycerol, $5 \mathrm{mM} \mathrm{MgCl}_{2}$ ). Proteins were detected by western blot using anti-FLAG (1:1,000 dilution; Sigma), anti-hemagglutinin (HA) (1:1,000 dilution; Sigma), anti-CypA (1:5,000 dilution; catalog number ab58144; Abcam), anti-TRIM5 $\alpha_{\text {hu }}(1: 1,000$ dilution; catalog number 14326S; Cell Signaling Technology), anti-glyceraldehyde-3-phosphate dehydrogenase (GAPDH) (1:5,000 dilution; Invitrogen), or anti-p24 (1:1,000 dilution, catalog number 3637; NIH) antibodies. Secondary antibodies against rabbit and mouse IgG conjugated to IRDye 680LT or IRDye $800 \mathrm{CW}$ were obtained from Li-Cor (1:10,000 dilution). Bands were detected by scanning blots using the Li-Cor Odyssey imaging system in the $700-\mathrm{nm}$ or $800-\mathrm{nm}$ channels.

\section{QUANTIFICATION AND STATISTICAL ANALYSIS}

Statistical analysis was performed using unpaired t test. Information on sample number, amount of repeats and $p$ value can be found in the corresponding figure legend. Quantification of the intensity of western blot bands was performed using ImageJ. For all experiments the mean and standard deviation values were calculated using GraphPad Prism 7.0c.

\section{DATA AND CODE AVAILABILITY}

This study did not generate any datasets or code. 